\title{
On the Potentials of Multiple Climate Variables in Assessing the Spatio-Temporal Characteristics of Hydrological Droughts over the Volta Basin
}

\author{
Christopher E. Ndehedehe ${ }^{\mathrm{a}}$, Joseph L. Awange ${ }^{\mathrm{a}, \mathrm{b}}$, Robert J. Corner ${ }^{\mathrm{a}}$, Michael Kuhn ${ }^{\mathrm{a}}$, \\ Onuwa Okwuashic \\ ${ }^{a}$ Western Australian Centre for Geodesy and The Institute for Geoscience Research Curtin University, Perth, \\ Australia \\ ${ }^{b}$ Department of Cartographic Engineering, UFPE Federal University of Pernambuco, Brazil \\ ${ }^{c}$ Department of Geoinformatics $\&$ Surveying, University of Uyo, P.M.B. 1017, Uyo, Nigeria
}

\begin{abstract}
Multiple drought episodes over the Volta basin in recent reports may lead to food insecurity and loss of revenue. However, drought studies over the Volta basin are rather generalised and largely undocumented due to sparse ground observations and unsuitable framework to determine their space-time occurrence. In this study, we examined the utility of standardised indicators (standardised precipitation index (SPI), standardised runoff index (SRI), standardised soil moisture index (SSI), and multivariate standardised drought index (MSDI)) and Gravity Recovery and Climate Experiment (GRACE) derived terrestrial water storage to assess hydrological drought characteristics over the basin. In order to determine the space-time patterns of hydrological drought in the basin, Independent Component Analysis (ICA), a higher order statistical technique was employed. The results show that SPI and SRI exhibit inconsistent behaviour in observed wet years presupposing a non-linear relationship that reflects the slow response of river discharge to precipitation especially after a previous extreme dry period. While the SPI and SSI show a linear relationship with a correlation of 0.63 , the correlation between the MSDIs derived from combining precipitation/river discharge and precipitation/soil moisture indicates a significant value of 0.70 and shows an improved skill in hydrological drought monitoring over the Volta basin during the study period. The ICA-derived spatio-temporal hydrological drought patterns show Burkina Faso and the Lake Volta areas as predominantly drought zones. Further, the statistically significant negative correlations of pacific decadal oscillations (0.39 and 0.25) with temporal evolutions of drought in Burkina Faso and Ghana suggest the possible influence of low frequency large scale oscillations in the observed wet and dry regimes over the basin. Finally, our approach in drought assessment over the Volta basin
\end{abstract}


contributes to a broad framework for hydrological drought monitoring that will complement existing methods while looking forward to a longer record of GRACE observations.

Keywords: Soil moisture, River discharge, Drought, Volta basin, SPI, Rainfall

\section{Introduction}

As a catchment shared by six riparian countries (i.e., Ghana, Burkina Faso, Togo, Ivory Coast, Benin, and Mali), the Volta basin (Fig. 1), which lies between latitudes $5^{\circ} \mathrm{N}$ to $14^{\circ} \mathrm{N}$ and longitudes $2^{\circ} \mathrm{E}$ to $5^{\circ} \mathrm{W}$ with an approximate area of $400,000 \mathrm{~km}^{2}$, is one of the poorest regions in Africa (Kasei et al., 2010). The region depends highly on rain-fed agriculture for its livelihood. Consequently, food security, the agrarian system, and economic development are threatened and highly vulnerable to the unreliable rainfall in the region (e.g., Lacombe et al., 2012). Kasei et al. (2010), specifically reported that the high variability in spatio-temporal rainfall distribution pattern was the major cause of fluctuation in food production while Bekoe and Logah (2013) showed that the hydrological drought years of 1983, 1998, 2003, and 2006 in the basin, which were evident from the strong decline of Lake Volta (a major physiographic feature in the basin) water levels, owing to rainfall decline, triggered limited production of electricity. Besides the seldom or rather infrequent scientific discussion probably due to limited and incomplete hydrological records, the drought story for the Volta basin is highly generalised due to lack of a suitable method to determine its spatio-temporal patterns.

Apparently, frequent extreme hydro-meteorological conditions (e.g., droughts and floods) may increase in the region due to the impacts of climate variability and coupled atmosphereocean phenomenon on rainfall variability. Climate phenomena is expected to exacerbate extreme drought tendencies and delayed rainfall in the Volta basin, where historical evidence from farmers suggests a seasonal forward shift in the onset of rain season (see, e.g., Giesen et al., 2010). This is probably true as global drying trends due to climate warming will ultimately impact on changes in hydrological conditions of the land surface. Also, the multiple strings of drought episodes in recent times, besides their negative impacts on water and energy balance (Owusu and Waylen, 2009), may have significant impacts on the economy and the agrarian system of the basin. For example, while food production was below normal in Ghana during the 1983 drought, food shortages of more than 50\% in Burkina Faso were recorded (Kasei et al., 2010). Further, given that approximately $27 \%$ of Ghana's $238,540 \mathrm{~km}^{2}$ land surface area is actually being cultivated, under a predominantly rain-fed agricultural system such as the Volta basin, the limited alimentation due to reduced rainfall in the northern boundary of 
mid-Ghana as reported by Owusu and Waylen (2013), is likely to prevent the cultivation of crops leading to food insecurity.

Away from Ghana, Burkina Faso which occupies $46.4 \%$ of the Volta basin (i.e., two-thirds of Burkina Faso is within the Volta basin) is one of the least urbanized countries in the world with about $90 \%$ of its population actively involved in the agricultural sector (see, Giesen et al., 2002). This level of active participation in rain-fed agriculture implies that if the observed drying trends in the Sahel (Greve et al., 2014), the shift in the onset of rainy season, and the 4th Assessment Report of the Intergovernmental Panel on Climate Change (IPCC), which re-emphasizes the dry gets drier paradigm (see, Giesen et al., 2010), are projections to go by, the region may be worst hit by food insecurity and poverty. In fact, in a recent study of local scale assessment and drought prediction (see, Nichol and Abbas, 2015), West Africa has been mentioned as one of the regions of the world that will be more susceptible to droughts due to climate change, leading to greater loss of livelihoods. From studies of precipitation sheds, it has been reported that even a small decline in rainfall could have tremendous impacts on agricultural yields in societies that rely on rain-fed agriculture (see, Keys et al., 2014, 2012). In view of the foregoing, understanding the space-time evolution of drought occurrence in the region will only be a logical step that unarguably can support comprehensive regional adaptation strategies, such as growing rain-fed crop cultivars (Giesen et al., 2010) and building water infrastructures that can increase water storage for future use, especially during extreme dry periods.

Unlike the Sahel region of West Africa, studies on drought in the Volta basin are relatively few and largely undocumented. This lack of regional studies on drought can partly be attributed to lack of ground-based information, as traditional gauge measurements are inconsistent, incomplete, and difficult to retrieve, owing to government bureaucracies, logistics, and the high cost of managing reliable in-situ stations over large heterogeneous landscapes. Considering the regional nature of drought, understanding their regional context in terms of their space-time development is critical. Furthermore, drought studies in the Volta basin, besides being less regional in nature, have only employed precipitation as a major climate variable. The problem with this, is that drought analyses based on a single climate variable (e.g., rainfall) for a region with high spatio-temporal variability, may not sufficiently describe drought phenomena in terms of its propagation and characteristics such as onset, duration, severity, frequency and intensity (e.g., Hao and AghaKouchak, 2014).

Further, Hao and AghaKouchak $(2013,2014)$ argued that for tropical regions, deficit in 
precipitation may not lead to a deficit in soil moisture, given the fact that agricultural drought (i.e., deficit in soil moisture) responds rather slowly to a meteorological drought (i.e., precipitation deficit) condition with some time lag. Following recent recommendation of using multiple climate variables (e.g., rainfall, river discharge, lake levels, groundwater, etc.) in studying hydrological drought characteristics (Long et al., 2015), a composite drought indicator, therefore, may significantly improve our understanding of hydrological drought (deficit in water availability usually in the form of low river discharge, abnormally low water levels in lakes, stream flow records, and groundwater level) characteristics (e.g., onset, duration, severity, frequency and intensity) over the basin.

However, few studies on the hydro-climatological conditions of the basin have been reported in recent times. Oguntunde et al. (2006) investigated hydrological variability and trends in the Volta River Basin during the period 1901-2002. They reported a higher runoff of $87.5 \mathrm{~mm} / \mathrm{yr}$ with coefficient of variation of $41.5 \%$ before dam construction compared to the post-dam period, when average runoff was $73.5 \mathrm{~mm} / \mathrm{yr}$ and less varied (i.e., with coefficient of variation of $23.9 \%$ ). Increased variability and declining rainfall totals associated with El-Niño Southern Oscillation (ENSO) phenomenon was reported by Owusu et al. (2008) as one of the devastating hydro-climatological changes in the basin. Furthermore, analysing long term precipitation data over Ghana for the period between 1951 and 2000, Owusu and Waylen (2009) reported large scale rainfall deficit with potential impacts on vegetation cover, water balance, and surface albedo that can trigger long-term below-normal rainfall. Using standardised precipitation index (SPI), Kasei et al. (2010) showed that the frequency of droughts in the Volta basin has increased since the 1970's. Also, trends in rainfall series were investigated at 16 stations in Ghana during the period of 1960-2005 using a resampling-based Mann-Kendall test statistics (Lacombe et al., 2012). Analysing daily rainfall data for the period between 1951 and 2000, Owusu and Waylen (2013) observed a widespread decline of mean rainfall totals and number of rain days during the minor rainy seasons. This aforementioned studies, though topical on the general drying trends and the hydrological conditions in the region, are highly generalised and less regional in nature. The implication of drought and hydrological studies that are less regional in nature is that observed trends and patterns that may be misconstrued as insignificant in a particular location (i.e., at a local or less regional scale), might be significant when evaluated at a regional scale ( e.g., Lacombe et al., 2012).

Further, the influence of local relief and the general southward shift in the seasonal movement of the Inter-Tropical Convergence Zone (ITCZ) are largely responsible for the rainfall 
variability in the basin (Lacombe et al., 2012; Owusu and Waylen, 2009). While rainfall in the Sahel region has a single peak mostly in summer, rainfall in the Guinea region, where the southern basin is located has a bimodal (i.e., two periods of wet seasons) seasonal distribution with two peaks occurring between May/October, with a short dry period (e.g., Ndehedehe et al., 2016; Odekunle and Eludoyin, 2008) in July/August separating the two peaks in rainfall (see, e.g., Lacombe et al., 2012; Owusu and Waylen, 2009). Hence, as argued by Owusu and Waylen (2009), the failure in the rainfall regime of a particular region does not necessarily mean the same for the other regions. Considering that different ocean circulation patterns and competing multiple physical mechanisms (Druyan, 2011) drive the variability of rainfall in the region, most drought related studies that have been reported in the region (see, e.g., Bekoe and Logah, 2013; Lacombe et al., 2012; Kasei et al., 2010) are rather generalised and not fully representative of the prevailing hydro-climatological condition of the basin at the time. Such generalizations may not be very useful for effective and robust planning of water resources and regional adaptation strategies in the event of extreme hydro-meteorological conditions (e.g., droughts and floods). With the north-south dichotomy in the rainfall mechanisms of the dry Sahel and wet Guinea regions of the Volta basin, a suitable methodology to monitor the space-time occurrence of drought episodes becomes essential.

In this contribution, we combine multiple hydrological quantities such as in-situ river discharge, Global Precipitation Climatology Centre (GPCC) based precipitation, soil moisture, evapotranspiration, and terrestrial water storage (TWS) derived from Gravity Recovery and Climate Experiment (GRACE, Tapley et al., 2004) in order to investigate the spatiotemporal characteristics of hydrological droughts and water storage changes over the Volta basin. GRACE-derived TWS has been widely used in the field of hydrology and studies of mass transport (see, e.g., Fukuda et al., 2009; Ramillien et al., 2008; Swenson and Wahr, 2007; Crowley et al., 2006) and represents the total sum of integrated water storage from catchment stores (i.e., groundwater, aquifer, soil moisture, and biomass water). We capitalize on GRACE observations to estimate the spatio-temporal trends in TWS over the basin, which like previous studies in the basin (see, e.g., Ferreira and Asiah, 2015; Ferreira et al., 2014), will be useful in understanding the basin's TWS and its water footprint, a measure of human's use of freshwater resources (e.g., Hoekstra and Mekonnen, 2012). In order to understand the space-time patterns and development of hydrological droughts over the basin, we used a higher order statistical decomposition method of independent component analysis (ICA, see, e.g., Cardoso, 1999; Common, 1994; Cardoso and Souloumiac, 1993) to localise the drought 
signals over the entire basin. The ICA approach, which enables the extraction of localised drought signals is different from previous studies (see, e.g., Bazrafshan et al., 2014; Santos et al., 2010) that have analysed spatio-temporal drought events in other regions of the world using principal component analysis (PCA, see, e.g., Jolliffe, 2002; Preisendorfer, 1988). The use of a statistical decomposition method such as the ICA is very helpful in understanding drought spatial variations and its temporal evolutions over the Volta basin, where a suitable framework for drought monitoring is lacking.

In addition, besides the use of standardised precipitation index (SPI, McKee et al., 1995, 1993), standardised soil moisture index (SSI, e.g., Mishra and Singh, 2010), and standardised runoff index (SRI, Shukla and Wood, 2008) to monitor hydrological drought of the Volta basin, we also used multivariate standardised index (MSDI, Hao and AghaKouchak, 2014; Farahmand and AghaKouchak, 2015) to evaluate the effectiveness of rainfall, soil moisture, and river discharge in capturing hydrological drought characteristics such as frequency (how often a drought event occurs), persistence, severity (the intensity of a drought event), and cessation. Specifically, this study aims at (i) characterising hydrological droughts over the Volta basin using multiple drought indicators such as SPI, SRI, SSI, and MSDI and (ii) characterising and localising space-time evolutions of hydrological drought patterns and TWS over the Volta basin.

While we provide a background information on the generalisations of drought patterns in Section 2, further details on the formulations of ICA and the results of the study are presented in Sections 3 and 4, respectively.

\section{On the Generalisations of Drought Patterns}

Owing to the influence of strong spatial variability of rainfall at annual scale coupled with the mean inter-annual climatological gradients across the region, the use of a single mean SPI computed from averaged rainfall data in estimating drought conditions over the Sahel hides the underlying spatial variability of the index (see, e.g., Ali and Lebel, 2009). As pointed out in Section 1, this may lead to generalisations of wet/dry regimes and might not be very helpful for modelling and planning purposes. Also, differences in the spatial resolutions of hydrological data, seasonal patterns, and influence of multiple ocean-atmosphere systems through the socalled climate teleconnections may complicate our understanding of drought evolutions and the water footprints of the region. Regardless of differences in the spatial resolution of the data and climatic zones and the influence of ocean-atmosphere systems, drought analysis from 
a spatio-temporal point of view can improve our understanding of drought occurrences and persistence.

The PCA method has been employed in spatio-temporal drought analysis thereby addressing some of these problems (see, e.g., Bazrafshan et al., 2014; Santos et al., 2010; Bonaccorso et al., 2003). To optimise on the performance of the PCA method, our approach employs a higher order statistical method, ICA, to localise the decomposed drought signals (SPI and SSI) obtained from the PCA process, by rotating them towards statistical independence. Further discussions on the proposed method and the standardised indicators are detailed in Section 3. The space-time evolutions of SPI and SSI through ICA then enables us to understand hydrological drought processes, their impacts and characteristics such as the onset, duration, intensity and spatial extent (Loon, 2015).

Furthermore, previous drought studies have associated hydrological drought with precipitation deficit on longer time scales such as 6, 9, 12, and 24 months cumulations (see, e.g., Li and Rodell, 2015; Lloyd-Hughes, 2012; Santos et al., 2010; Nalbantis and Tsakiris, 2009; Hayes, 2007; Vicente-Serrano, 2006; Rouault and Richard, 2003; Hayes et al., 1999; Komuscu, 1999). More recently, it has been shown that region averaged groundwater drought index from the Princeton forced catchment land surface model (CLSM) and in-situ groundwater observations, exhibited stronger correlation with SPI at 12 and 24 month cumulation, reflecting the lagged response of groundwater to rainfall anomalies (Li and Rodell, 2015). To this end, in our spatio-temporal drought analysis, we used long term precipitation and soil moisture data, covering a 63-year period (1950-2013) to characterise and quantify hydrological drought frequency and severity in the basin. Also, similar to Li and Rodell (2015), Santos et al. (2010) and Hayes et al. (1999) we used 12 and 24 month's cumulations of SPI and SSI, hypothesizing that this longer time scales for the rainfall and soil moisture drought indices will provide the capability to monitor drought and wet conditions suitable for hydrological applications in the Volta basin.

\section{Data and Method}

\subsection{Data}

\subsubsection{Gravity Recovery and Climate Experiment (GRACE)}

The GRACE (Tapley et al., 2004) satellite mission, which has been in operation since March 2002, provides an integrated sum of changes in catchment stores (e.g., groundwater, soil moisture, etc.) based on observations of the Earth's time variable gravity fields. The 


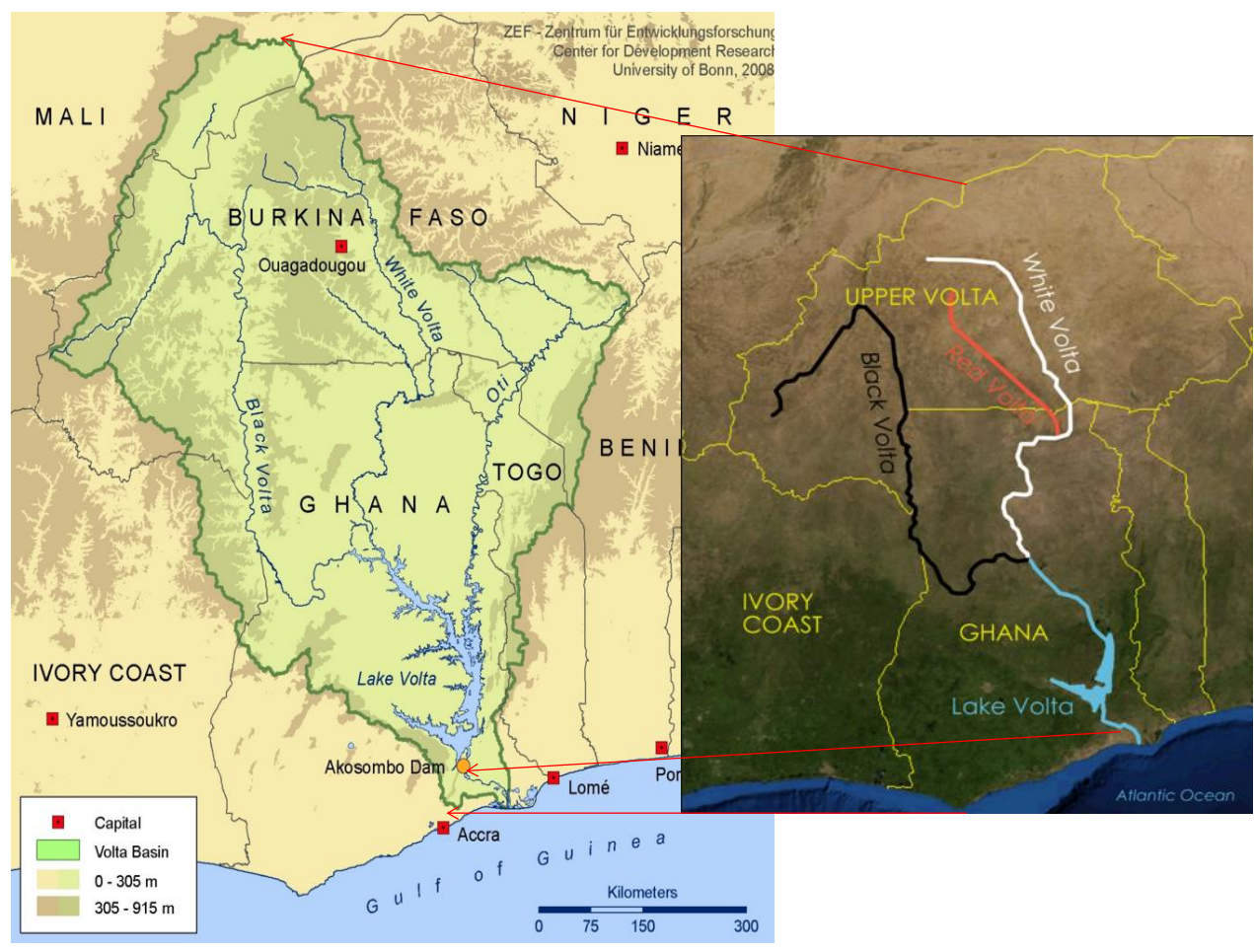

Figure 1: Study area showing the riparian countries of the Volta Basin and the Lake Volta area in Ghana. The Volta river system comprising the Black Volta, White Volta, and the Oti river is also indicated. Original Map adapted from http://www.21stcentech.com/wp-content/uploads/2013/12/Volta-River-basin.jpg.

GRACE Release-05 (RL05) spherical harmonic coefficients from Center for Space Research (CSR), truncated at degree and order 60 and covering the period from April 2002 to October 2014 was used in the study to estimate TWS. Since GRACE does not provide changes in degree 1 gravity coefficients (i.e., $C_{10}, C_{11}$, and $S_{11}$ ), and is also affected by large tide-like aliases in the degree 2 coefficients (i.e., $C_{20}$ ), we followed conventional procedures of using degree 1 gravity coefficients that are determined from ocean and atmospheric models (Swenson et al., 2008) and substituting degree 2 coefficients with estimates from satellite laser ranging (Cheng et al., 2013). The spherical harmonic coefficients are thereafter filtered using the DDK2 decorrelation filter of Kusche et al. (2009) in order to reduce the effect of correlated noise. Equivalent water heights (hereafter called TWS) are then derived on a $1^{\circ} \times 1^{\circ}$ grid from the filtered monthly solutions following the method of Wahr et al. (1998):

$$
\triangle S(\phi, \lambda, t)=\frac{R \rho_{\text {ave }}}{3 \varrho_{w}} \sum_{l=0}^{l_{\max }} \frac{2 l+1}{1+k_{l}} \sum_{m=-l}^{l} P_{l m}(\phi, \lambda) \triangle Y_{l m}(t),
$$

where $\triangle S$ is the change in TWS for each month in time $(t)$, and where $\phi, \lambda$ are latitudes and longitudes respectively. $\mathrm{R}$ is the radius of the Earth taken to be $6378.137 \mathrm{~km}, \rho_{\text {ave }}$ is the average density of the Earth $\left(5515 \mathrm{~kg} / \mathrm{m}^{3}\right), \varrho_{w}$ is the average density of water $\left(1000 \mathrm{~kg} / \mathrm{m}^{3}\right), k_{l}$ 
is the load Love numbers of degree $l, P_{l m}$ are the normalized associated Legendre functions of degree $l$ and order m with $l_{\max }=60$ and $\triangle Y_{l m}$ are the normalized complex spherical harmonic coefficients after subtracting the long term mean. The DDK2 decorrelation filter with a degree of smoothing corresponding to that of a Gaussian filter with a $340 \mathrm{~km}$ radius (Kusche et al., 2009) causes a reduction in the amplitude of observed GRACE signal (e.g., Wouters and Schrama, 2007; Baur et al., 2009). This was remedied by following approaches in previous studies (see, e.g., Long et al., 2015; Landerer and Swenson, 2012; Fenoglio-Marc et al., 2012), where a scale factor derived from hydrological models was used to account for the impact of the filtering on GRACE observations. The random data gaps for the 12 missing months in the GRACE-TWS solutions were filled through an interpolation method that uses values at neighboring data points. Further, averaged TWS values over the basin, were computed using the area weighted average (see, e.g., Tourian et al., 2015; Sneeuw et al., 2014):

$$
\triangle W(\chi ; t)=\sum_{l=1}^{n} \triangle W\left(\phi_{i}, \lambda_{i}, t\right) \frac{A_{i}}{A_{\chi}},
$$

where $\chi$ is the basin index, $n$ is the number of pixels in the basin, $A_{i}$ is the area of the grid cell $i$ in $\chi$ and $A_{\chi}$ is the total area of $\chi$.

\subsubsection{Global Precipitation Climatology Centre (GPCC)}

The monthly gridded GPCC (Schneider et al., 2014; Becker et al., 2013) based precipitation product covering the period 1950 to 2014 is used in the study for the construction of SPI and long-term rainfall analysis over the Volta basin. The $0.5^{\circ} \times 0.5^{\circ} \mathrm{GPCC}$ data, which is accessible through the GPCC download site (www.ftp.dwd.de/pub/data/gpcc/html/down/loadgate.html) was also combined with in-situ river discharge to estimate MSDI over the basin. The GPCC based precipitation uses about 67,200 rain gauge stations over global land areas and has been compared with other in-situ based precipitation such as the Global Precipitation Climatology Project (GPCP) (see Schneider et al., 2014). Specifically, over West Africa the GPCC based precipitation shows good agreement with Tropical Rainfall Measuring Mission (TRMM), which has been validated over the region (e.g., Awange et al., 2016; Ndehedehe et al., 2016; Paeth et al., 2012; Nicholson et al., 2003).

\subsubsection{Climate Prediction Center (CPC) Soil Moisture}

Monthly CPC soil moisture data (Fan and Dool, 2004), at spatial resolution of $0.5^{\circ} \times 0.5^{\circ}$ was used for spatio-temporal drought analysis through the construction of SSI over the basin. 
Also, averaged time series of soil moisture over the basin was combined with GPCC-based precipitation to construct MSDI, in addition to deriving SSI. The CPC soil moisture data is estimated using more than 17,000 rain gauges worldwide and monthly global temperature from reanalysis. The data used in this study covers the period between 1950 to 2014 and is freely available at National Oceanic and Atmospheric Administration's (NOAA) website for download (www.esrl.noaa.gov/psd/data/gridded/data.cpcsoil.html).

\subsubsection{MODIS Global Terrestrial Evapotranspiration Project}

The improved version of MODIS global terrestrial evapotranspiration products by $\mathrm{Mu}$ et al. (2011) was combined with precipitation in this study to estimate net precipitation, a measure of the maximum available renewable freshwater resource. The data, which has a spatial resolution of $0.5^{\circ} \times 0.5^{\circ}$ covers the period $2000-2014$ and is available for download at the Earth Observing System of NASA's website (http://www.ntsg.umt.edu/project/mod16).

\subsubsection{In-situ River Discharge data}

Observed monthly discharge rates at Akosombo Dam, in Ghana were used to construct SRI. It was also combined with the GPCC-based precipitation to construct MSDI in order to analyse hydrological drought over the basin. The data covering the period 1979-2012 was obtained from the Water Research Institute of Ghana.

\subsubsection{Climate Teleconnection Indices}

In order to examine the possible connections of observed temporal evolutions of the statistically decomposed drought signals over the Volta basin with coupled atmosphere-ocean system, relevant global climate teleconnection indices such as the North Atlantic Oscillation (NAO), Pacific Decadal Oscillation (PDO) and Arctic Oscillation (AO) were investigated through correlation analysis. In particular, PDO has been linked to the decadal variability of Sahel rainfall (e.g., Rodrguez-Fonseca et al., 2011) while the influence of NAO on the local climate of the region has been reported (e.g., Okonkwo, 2014). Time series of these data sets covering the period 1950-2013 were downloaded from NOAA's website (http://www.ncdc.noaa.gov/ teleconnections).

\subsection{Method}

\subsubsection{Multiple Linear Regression Analysis (MLRA)}

This study used a multiple linear regression model to parameterize the cosine and sine harmonic components (i.e., the annual and semi-annual signals) of monthly GRACE-derived 
TWS changes. This is obtained as

$$
\mathbf{D}=\mathbf{X}-\left(\beta_{0}+\beta_{2} \sin (2 \pi t)+\beta_{3} \cos (2 \pi t)+\beta_{4} \sin (4 \pi t)+\beta_{5} \cos (4 \pi t)\right),
$$

where $\mathbf{D}$ is the deseasonalize GRACE-derived TWS with harmonic components removed, $\mathbf{X}$,

is the data, $\beta_{0}$ is the constant offset, $\beta_{2}$ and $\beta_{3}$ accounts for the annual signals while $\beta_{4}$ and $\beta_{5}$ represents the semi-annual signals. The annual signals of TWS were separated from the GRACE-TWS and the residual, which comprises the semi-annual signals and trends were further analysed using the ICA method (see Section 3.2.2).

\subsubsection{Statistical Decomposition Methods}

ICA (see, e.g., Cardoso and Souloumiac, 1993; Cardoso, 1999), a higher order statistical technique usually referred to as blind source separation in signal processing (e.g., Cardoso, 1999) has emerged as a more suitable alternative in the decomposition of multivariate data into statistically independent signals. Recently, it has been used to separate relevant geophysical signals into their statistically independent components (see, e.g., Boergens et al., 2014; Awange et al., 2014; Forootan et al., 2012; Frappart et al., 2011). We have used it as an improvement to the PCA method, which has been applied to analyse drought signals and spatio-temporal variability of TWS in previous studies (e.g., Ndehedehe et al., 2016; Santos et al., 2010; Bonaccorso et al., 2003). In this study, it is used to localise drought signals over the Volta basin in order to provide a better understanding of the space-time patterns of droughts. Prior to implementing ICA, the PCA method is used to identify statistically significant modes of variability in the computed gridded SPI, SSI values and GRACE-derived TWS. Subsequently, the derived statistically significant dominant patterns are further explored through a classical rotation of the principle components, using the Joint Approximate Diagonalisation of Eigen matrices (JADE) algorithm fully described in Cardoso and Souloumiac (1993) and Cardoso (1999). The JADE algorithm is statistical based and follows a Jacobi technique (so called because they seek to maximize measures of independence by a technique similar to the Jacobi method of diagonalization) in the process of orthogonal contrast optimization, different from other ICA online solutions that uses the gradient techniques (Cardoso, 1999). Fundamentally, ICA decomposes a data matrix $x_{i}(t)$, which consist of a number of statistically independent source signals $s_{j}(t)$ where $t$ is the time index. This can be expressed as (e.g., Ziehe, 2005)

$$
x_{i}(t)=\sum A_{i j} s_{j}(t), \quad(i=1, \ldots, n, \quad j=1, \ldots, m),
$$


$x_{i}$ in Eq. 4 is the mixing model or the linear mixture and can be represented as a matrix for notational convenience as

$$
\mathbf{X}=\mathbf{A S}
$$

where the entries of the data matrix $\mathbf{X}$ are samples of the $x_{i}(t)$ given in Eq. 4 leading to column vectors $x[t]=\left[x_{1}[t], \ldots, x_{n}[t]\right]^{T}$, the $\mathrm{n} \mathrm{x} \mathrm{m}$ matrix $\mathbf{A}$ has elements $A_{i, j}$ and the source signals i.e., matrix $\mathbf{S}$, similar to the construction of $\mathbf{X}$, has column vectors $s[t]=\left[s_{1}[t], \ldots, s_{m}[t]\right]^{T}$. Two major challenges of ICA lies in the definition of a measure of independence and the choice of algorithms to find the change of basis (or separating matrix) that fully optimizes this measure (Cardoso, 1999). These measures of independence are based on cumulant-based blind identification of the separation matrice. The fourth-order cumulant matrix is expressed as

$$
\mathbf{C}_{i, j}(\mathbf{M})=\sum \mathbf{M}_{u, v} \operatorname{cum}\left(x_{i}, x_{j}, x_{u}, x_{v}\right)
$$

where $\mathbf{M}$ is an arbitrary matrix (see, e.g., Ziehe, 2005). The plane rotations are applied to these Cumalant-based matrices to estimate the independent components through a multiplicative update of an estimate of the separation matrix. Further theoretical details of these cumulantbased methods and ICA in general are provided in the works of Cardoso (1991), Cardoso and Souloumiac (1993), Common (1994), Cardoso (1999), Ziehe (2005), Theis et al. (2005), and Forootan and Kusche (2012). The ICA algorithm available at http://perso.telecomparistech.fr/cardoso/Algo/Jade/jadeR.m was used to decompose standardised drought indicators (SPI and SSI data) and GRACE-derived TWS into spatial and temporal patterns. After the decomposition, the independent components were normalised using their standard deviations to be unitless. Each ICA mode is a combination of the temporal and spatial patterns and are usually interpreted together (i.e., the unit-less temporal evolution is multiplied with the spatial pattern in order to obtain the actual values).

\subsubsection{Standardised drought Indices}

A drought index is a significant variable used for the assessment of the impacts of droughts and defining several drought properties such as duration, severity, intensity, and spatial extent (Mishra and Singh, 2010). In this study, four different drought indices (SPI, SSI, SRI, and MSDI) were used to quantify and analyse a drought event. Our standardised drought indices follow the non-parametric approaches of Hao and AghaKouchak (2014) and Farahmand and AghaKouchak (2015) where instead of gamma distribution function, an empirical approach was 
used to derive the marginal probability using the univariate form of the Gringorten plotting position (Gringorten, 1963). The joint distribution of two variables $X$ and $Y$ is expressed as

$$
P(X \leq x, Y \leq y)=\rho
$$

where $\rho$ represents the joint probability of any two variables (e.g., rainfall and soil moisture). The joint probability is used to define the MSDI (Hao and AghaKouchak, 2013) as

$$
M S D I=\phi^{-1}(\rho)
$$

where $\phi^{-1}$ is the standard normal distribution function. For the bivariate case, the Gringorten plotting position formula (Gringorten, 1963) reported by Farahmand and AghaKouchak (2015) is used to estimate the empirical joint probability. The empirical Gringorten plotting position expressed as

$$
p\left(x_{k}, y_{k}\right)=\frac{m_{k}-0.44}{n+12}
$$

where $\mathrm{n}$ is the number of the observation and $m_{k}$ is the number of times which the pair $\left(x_{i}, y_{i}\right)$ occurs for $x_{i} \leq x_{k}$ and $y_{i} \leq y_{k}(1 \leq i \leq n)$. Eq. 9 is applied in Eq. 8 to estimate the MSDI while the SPI, SSI, and SRI are also estimated using the univariate form of Eq. 9. Since it has been argued that a single drought index may not satisfactorily describe different aspects of drought onset, duration and termination (see Farahmand and AghaKouchak, 2015; Hao and AghaKouchak, 2014, 2013), we combined on one hand, rainfall and river discharge data and on the other hand, rainfall and soil moisture data to estimate two different sets of MSDI over the basin, in addition to the single indicators (i.e., SPI, SSI, and SRI). Add to this, the gridded drought indicators (i.e., SPI and SSI) at 12 and 24 month time scales were also estimated and statistically decomposed using the ICA method (see Section 3.2.2) in order to understand their spatio-temporal variability for hydrological applications. The relationship between the two categories of MSDI's was obtained through Pearson correlation analysis while the relationship between the pairs SPI/SSI, and SRI/SPI was also examined through the same process.

\section{Results and Discussions}

\subsection{The Potential of Standardised Indicators in Characterising Hydrological Drought}

Hydrological droughts refer to the period with insufficient water in the hydrological system. This is usually evident in shortages of surface and sub-surface water resources for established 


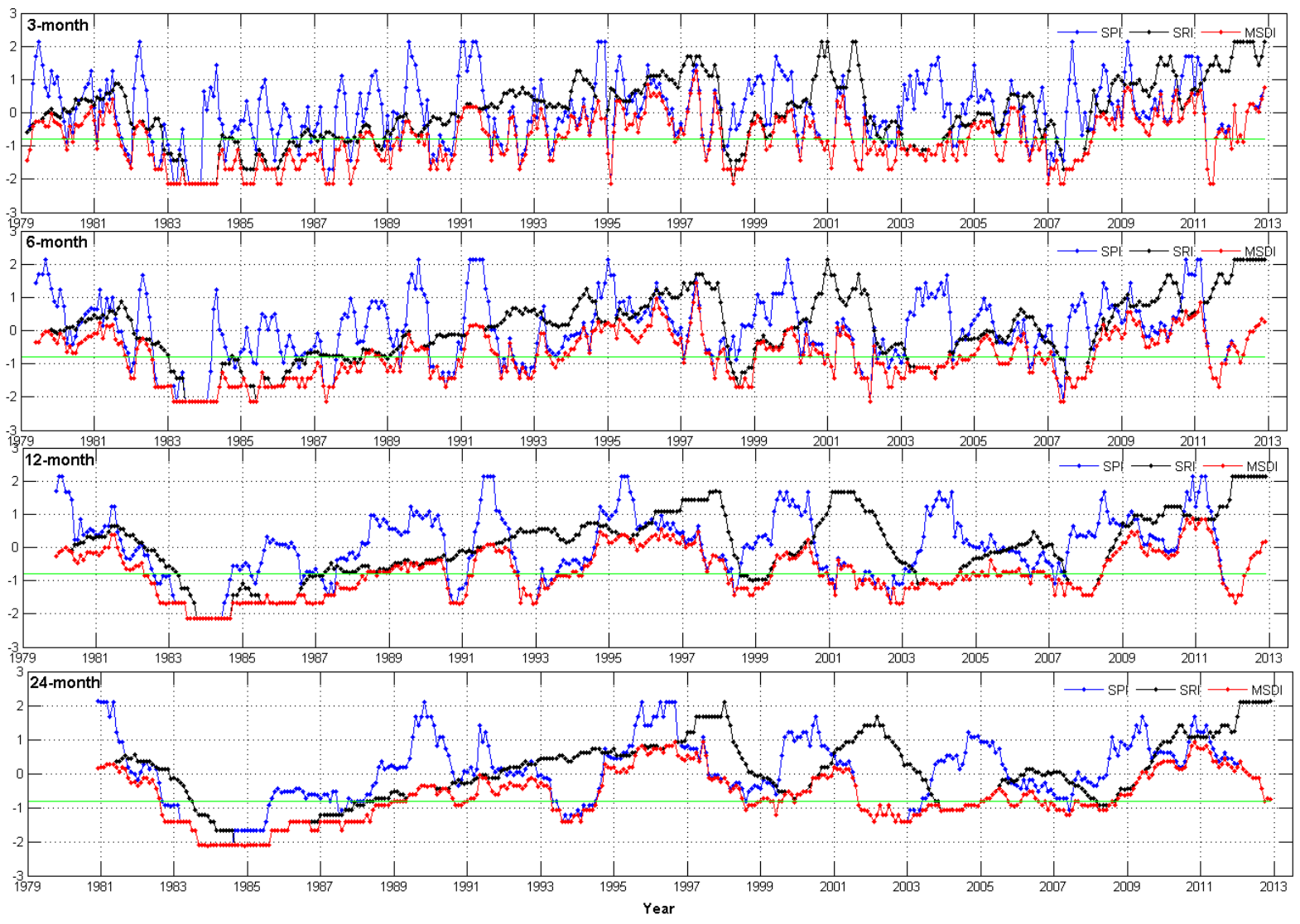

Figure 2: Time series of standardised drought indicators (SPI, SRI, and MSDI) for the Volta basin based on GPCC-based precipitation and in-situ river discharge data at Akosombo station covering the period 1979-2013. MSDI is derived through the combination of GPCC-based precipitation and in-situ river discharge. These standardised drought indicators are based on empirical probability. The green solid line is drought threshold based on the description of McKee et al. (1993).

use and relevant applications in a given water resources management system (Mishra and Singh, 2010). The lack of comprehensive in-situ observations at local or regional scales has encouraged the use of proxies and indices to quantify hydrological droughts (Kumar et al., 2015). To this end, we assessed the capability of three different standardised indicators (SPI, SRI, SSI) and their corresponding multi-index (MSDI), constructed using a non-parametric approach (Hao and AghaKouchak, 2014). The drought threshold level was defined similar to the SPI values of McKee et al. (1993) in order to support a better understanding of drought severity, duration, and intensity.

Results for the computed drought indices for 3, 6, 12, and 24 months cumulation over the Volta basin using a 34-year data record are indicated in Figs. 2 and 3. Two MSDIs were derived by combining rainfall and river discharge (Fig. 2) and rainfall and soil moisture (Fig. 3). Despite the poor correlation between SPI and SRI (0.11), the acknowledged hydro- 
logical drought years of 1983/1984, 1997/1998, 2003 and 2006/2007 that resulted in electricity power rationing in Ghana (Bekoe and Logah, 2013) have been captured by the two indices in all monthly cumulations (Fig. 2). Extreme wet periods tend to exhibit some lagged relationships, reflecting some significantly slow response of discharge (SRI) to extreme wet condition (SPI), especially after a previous extreme dry period. For instance, over longer time scales (i.e., 6, 12 and 24 months), the SRI responded to the extreme wet conditions of 1989, 1991, 1995 as a gradual rise starting from 1989 and peaking at 1997 (Fig. 2), a known hydrological drought year in the basin. Still on the relationship of rainfall and river discharge in the Volta basin, Friesen et al. (2005), observed that runoff had a much higher coefficient of variation (CV) (0.38) for the period between 1931 and 2005 while rainfall had a CV of 0.08 during the same period, leading to a non-linear response that amplified small changes in rainfall to large changes in runoff. Generally, the hydrological behaviour of the basin indicates some time lag (about 1-2 years) between the response of discharge to wet and dry conditions, in addition to a non-linear behaviour that could be amplified by the impacts of ocean circulations and perturbations on annual and seasonal rainfall. From our SPI result (Figs. 2 and 3), 2003 was a rather wet year consistent with the findings of Bekoe and Logah (2013). However, the SRI and the corresponding MSDI both indicated severe drought conditions in 2003 and 2004 in all time scales. This can be attributed to the impact of the previous drought years $(2001 / 2002)$, indicating the filtering effect of the catchment storage conditions. Also, this kind of out-ofphase relationship or rather still inconsistent behaviour, which was also reported by Hao and AghaKouchak (2013) for a different study, can also result from abnormally high precipitation lasting for a short period of time, while several other months within the same year remain dry (e.g., the 2007 period in the basin shows the same behaviour due to an ENSO event).

By and large, the MSDI derived from the combination of SPI and SRI demonstrates substantially a level of consistency and reliability in that the true representation of the hydrological drought situation is highlighted as the low water level of Lake Volta in 2003 (see, Fig. 2) actually resulted in limited hydro-power generation. It seems that profound and extreme drought conditions over the basin do have a rather strong signature that makes these hydrological quantities (e.g., rainfall, river discharge, and soil moisture) respond to its onset, persistence and termination. For example, despite the rather weak correlation of 0.11 at $95 \%$ confidence level between SPI and SRI, the acknowledged extreme hydrological drought years of 1983-1985, 1998, and early 2007 are all captured by the two indices. Further, it can be argued that due to increased irrigation schemes in the basin (e.g., Andreini et al., 2002) leading to increased 
use of surface waters in Burkina Faso, the inflow into the lower Volta basin in Ghana (i.e., the Lake Volta) where the river discharge at Akosombo station is observed will be largely reduced. Consequently, this may limit the potential of river discharge in assessing a hydrological drought condition in the basin. However, as observed in Fig. 2, an estimated lead time of 1-2

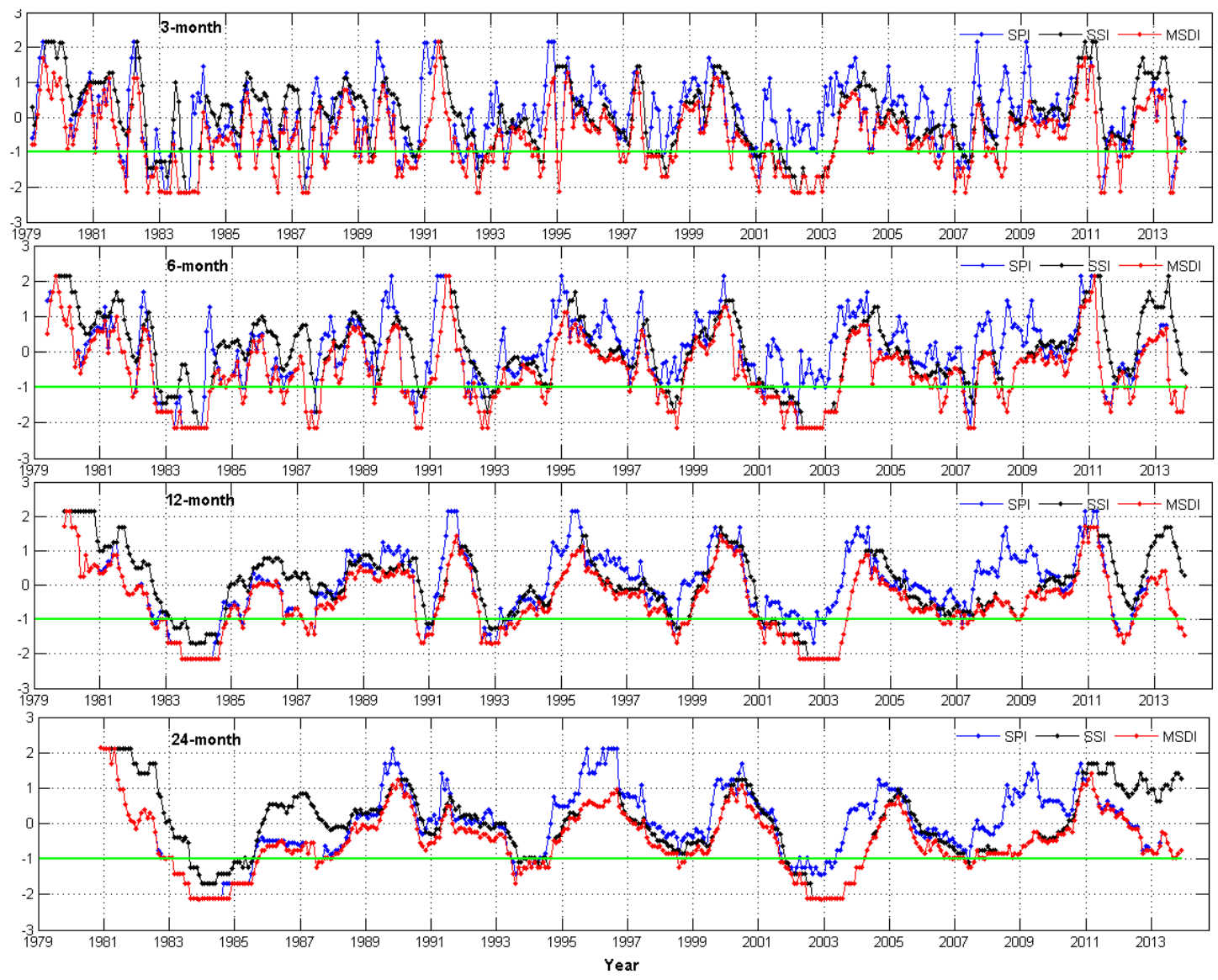

Figure 3: Time series of standardised drought indicators (SPI, SSI, and MSDI) for the Volta basin based on GPCC-based precipitation and CPC soil moisture data covering the period 1979-2013. MSDI is derived through the combination of GPCC-based precipitation and CPC soil moisture. These standardised drought indicators are based on empirical probability. The green solid line is drought threshold based on McKee et al. (1993) description.

years can be applied to accumulation periods of 6,12 , and 24 month SPI in order to forecast a hydrological drought condition over the basin. For instance, the hydrological drought condition of 2011/2012 from the SPI 6 and 12 month accumulation period (Fig. 2) will be evident in the discharge rate in 2013/2014 period. This was confirmed in the satellite altimetry data (not shown) where Lake Volta, which is formed by the Akosombo Dam in Ghana is already showing a relatively strong negative anomaly in water levels similar to the 2003 and 2007 period observed in this study (see, Fig. 2).

On the other hand, SPI and SSI showed a significant correlation of 0.63 (i.e., at 12 month 
scale) at 95\% confidence level indicating consistency in observed wet and dry periods (Fig. 3). At longer time scales, the SPI/SSI-derived MSDI has shown that the drought conditions of 2001/2002 persisted till 2003, in addition to indicating well known hydrological drought years of 1983/1984, 1997/1998, 2002/2003, 2006/2007 mentioned previously (Fig. 3). Also, SPI and SSI have shown some consistent behaviour that indicates a linear relationship with almost no time lag over the basin. In some studies (Kumar et al., 2015), the effectiveness of SPI as a meteorological drought index in translating precipitation deficits to a hydrological drought condition has been questioned probably due to its non-linear relationship with other hydrological variables, e.g., groundwater and river discharge, which is also observed in the current study. However, at longer time scales, Li and Rodell (2015) recently showed that changes in groundwater are tightly coupled to precipitation variability, which could be in the short term (i.e., SPI 6 month cumulation) or long term (i.e., SPI 12 and 24 month cumulation). Apparently, this relationship between rainfall and groundwater and other catchment stores (e.g, aquifer, sub-surface and runoff) can be influenced by the depth to the water table and precipitation rates as the land surface part of the hydrological cycle acts as a low-pass filter to the meteorological forcings (e.g., Loon, 2015; Li and Rodell, 2015).

Further, Bonsor and MacDonald (2011) and MacDonald et al. (2012) demonstrated the importance of rainfall and geomorphology/weathering parameters as input for developing and estimating groundwater maps showing depth over Africa. Much of the Volta basin, especially the seasonally wet areas (e.g., Ghana and Togo) as shown in the developed groundwater map of Africa (MacDonald et al., 2012) are regions with the shallowest groundwater-levels (i.e., $<7 \mathrm{mgbl}$ ) compared to the Central Sahel (i.e., the region North of the basin) where depth to groundwater ranges from 50-250 mbgl. Given the relationship between rainfall and other hydrological quantities such as recharge, runoff, groundwater and discharge, the propagation of a meteorological drought (SPI) in the Volta basin to a hydrological drought condition is inferred, consistent with Bloomfield and Marchant (2013) who observed a good correlation and a site-specific relationship between standardised groundwater level index and SPI in a similar study in the UK.

In view of this, we align with the fact that observed precipitation and soil moisture deficits at 12 and 24 month accumulations over the Volta basin are typical of hydrological droughts as indicated in recent studies (Li and Rodell, 2015; Joetzjer et al., 2013; Lloyd-Hughes, 2012; Santos et al., 2010; Nalbantis and Tsakiris, 2009; Hayes, 2007). While it is true that prolonged precipitation deficit fundamentally reduces alimentation of a given hydrologic system, Loon 

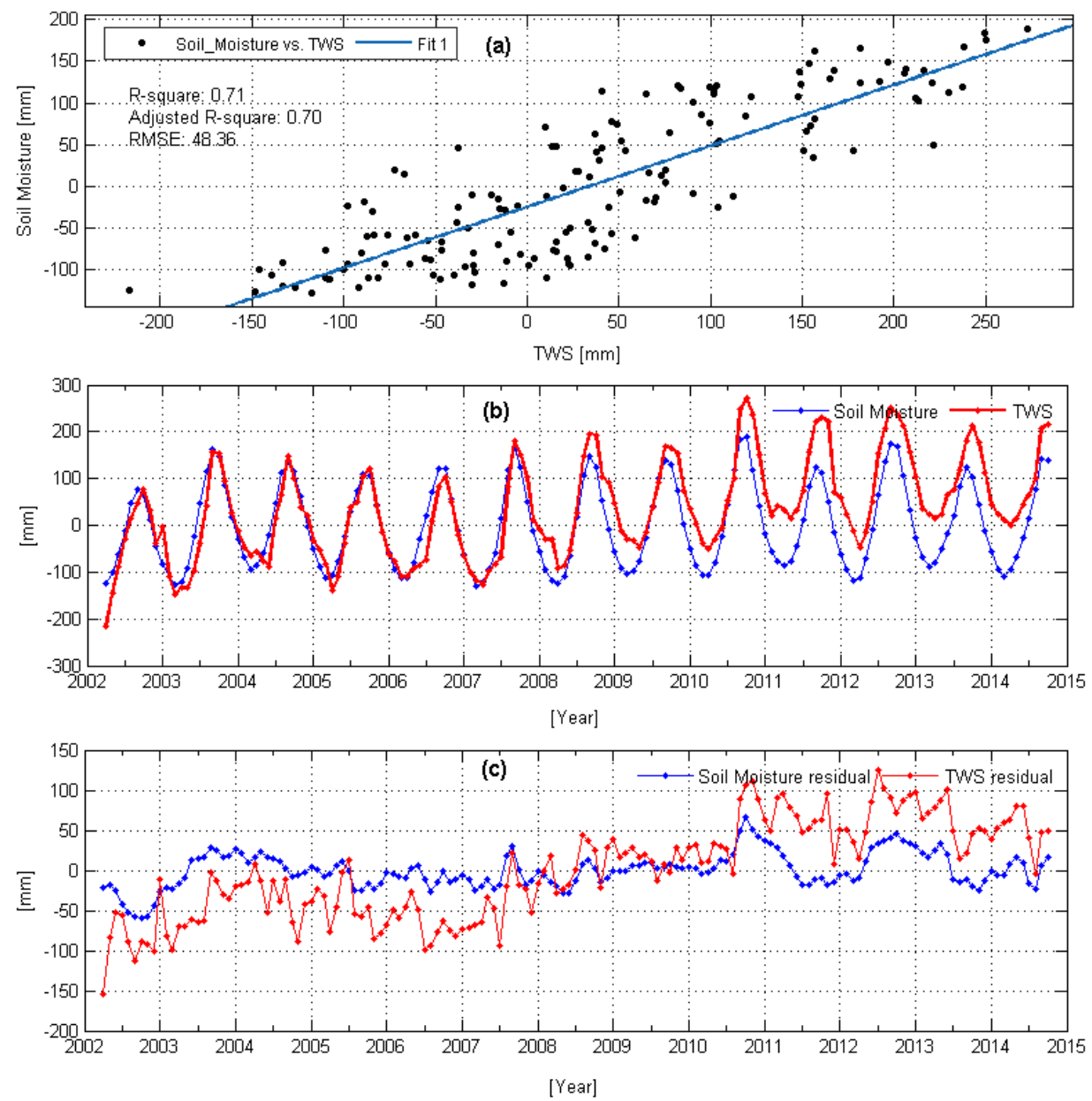

Figure 4: Relationship of TWS anomalies and soil moisture over the Volta basin covering the period 20022014. (a) Regression fit on GRACE-derived TWS changes and soil moisture change. (b) Temporal variations of averaged TWS changes and soil moisture over the Volta basin. (c) Time series of deseasonalized averaged TWS changes and soil moisture (i.e after removing the annual and semi annual components.

(2015) remarked that the depletion of soil moisture storage leads to decreased recharge and decline in groundwater levels. Interestingly, the correlation between the two MSDI's computed using rainfall/river discharge and rainfall/soil moisture show a good correlation of 0.70 at 95\% confidence level, indicating consistency in drought and wet periods captured (see, Figs. 2 and 3). The multi-index approach (i.e., the MSDI), which assesses drought based on multiple variables links individual drought indicators (i.e., SPI, SRI, and SSI) into a composite model (Farahmand and AghaKouchak, 2015), thereby providing a more robust assessment of droughts. Due to its improved skill and the capability to feature drought onset and persistence, the use of MSDI (in longer aggregation time scales such as 12 and 24 month) to analyse hydrological drought over the Volta basin is recommended. 

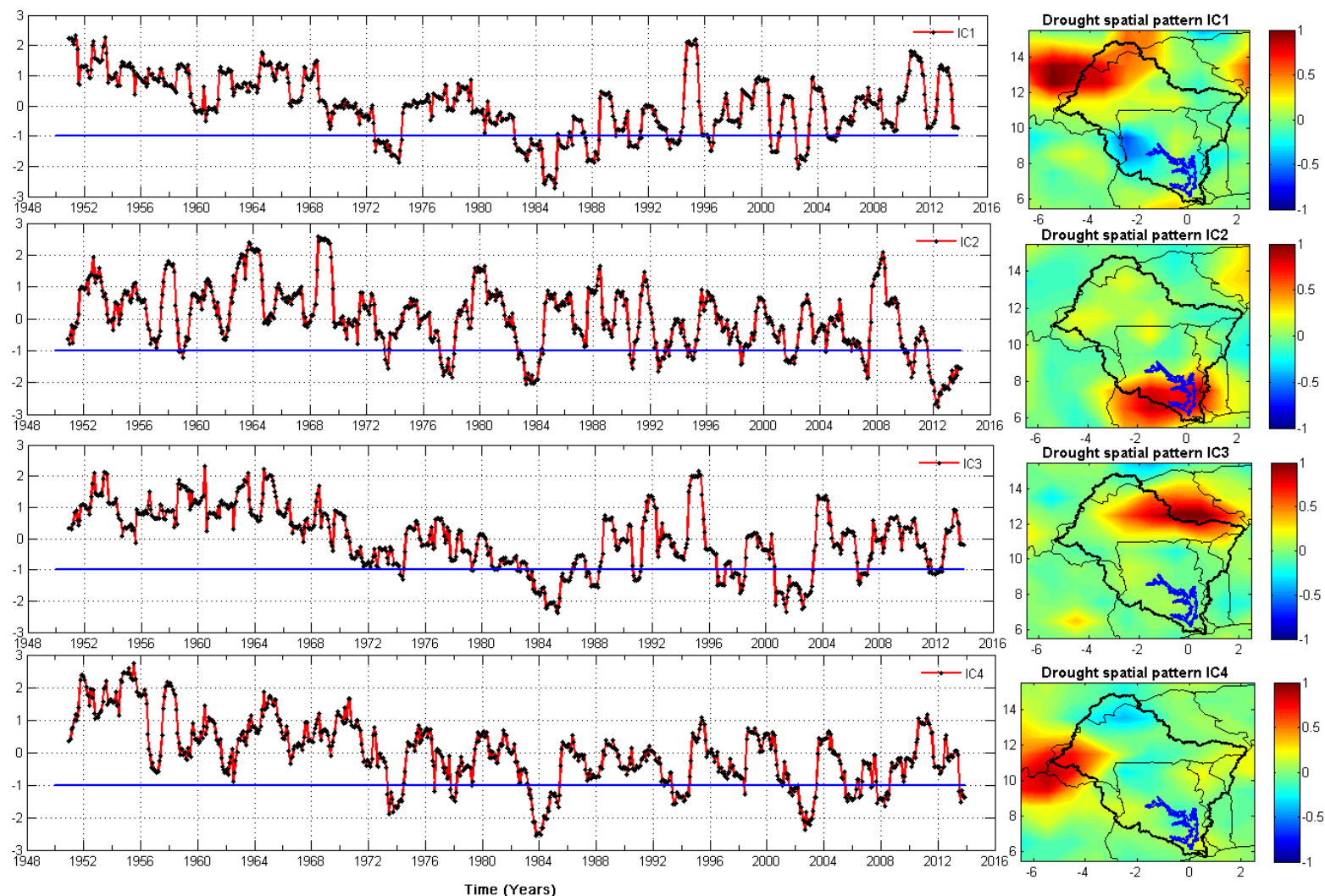

Figure 5: ICA-derived spatio-temporal hydrological drought patterns over the Volta basin using 12-month gridded SPI values. SPI values are computed using GPCC-based precipitation for the period 1950-2013. The variability of the ICA modes (i.e., the spatial and temporal drought patterns) for the decomposed SPI values within the basin are $10.7 \%, 6.7 \%, 6.6 \%$, and $6.3 \%$ for IC1, IC2, IC3, and IC4, respectively. Actual SPI values for drought classification and categorisation are jointly derived from the localised spatial drought pattern (right) and their corresponding temporal evolutions (left). The blue solid line shows the drought threshold based on McKee et al. (1993) description.

\subsection{Spatio-temporal Variability of Hydrological Drought Over the Volta Basin}

The spatio-temporal variability of hydrological drought was investigated using long term GPCC-based precipitation and CPC soil moisture data. While the use of SPI at longer time scales as hydrological drought proxies have been reported (e.g., Li and Rodell, 2015; Loon, 2015; Bloomfield and Marchant, 2013; Santos et al., 2010), the use of SSI in similar context is largely undocumented. To this end, we examined the potential of soil moisture as a surrogate for TWS over the Volta basin, in order to effectively quantify drought events significant to hydrological applications. This has been achieved through a least squares fit. The regression fit between rainfall and soil moisture over the basin showed adjusted $R^{2}$ of 0.7 indicating that most parts of the basin are consistent with observed trends and variability in TWS (see, Fig. 4a and b). Besides the significant correlation of 0.84 at $95 \%$ confidence level observed between 
the two variables (i.e., TWS and soil moisture), the period between 2002 and 2007 as indicated in Fig. 4b appears to have temporal variations with similar strong peaks (i.e., maximum and minimum). However, after removing the annual and semi-annual signals from the time series
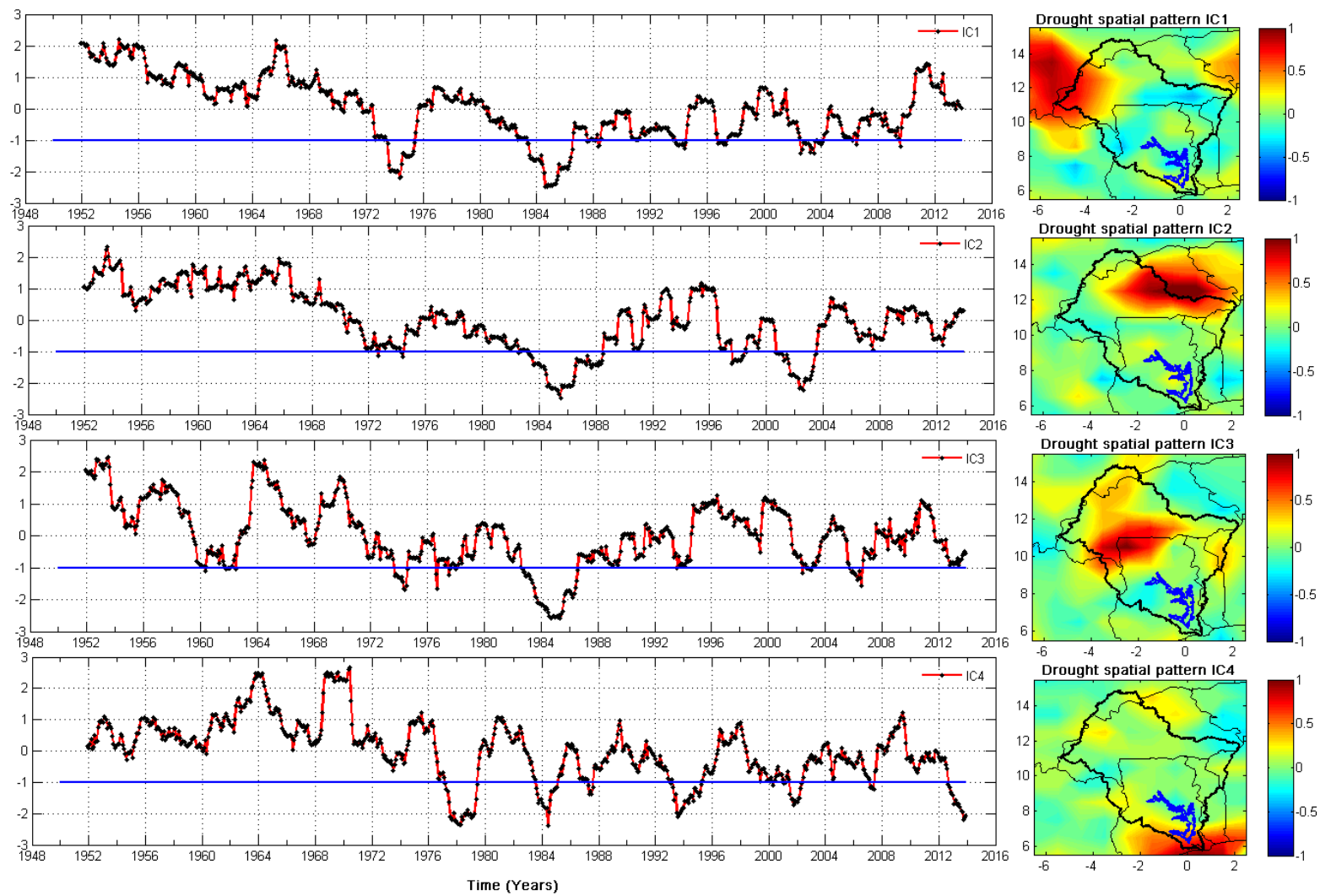

Figure 6: ICA-derived spatio-temporal hydrological drought patterns over the Volta basin using 24-month gridded SPI values. SPI values are computed using GPCC-based precipitation for the period 1950-2013. The variability of the ICA modes (i.e., the spatial and temporal drought patterns) for the decomposed SPI values within the basin are $10.9 \%, 9.0 \%, 6.6 \%$, and $6.5 \%$ for IC1, IC2, IC3, and IC4, respectively. Actual SPI values for drought classification and categorisation are jointly derived from the localised spatial drought pattern (right) and their corresponding temporal evolutions (left). The blue solid line shows the drought threshold based on McKee et al. (1993) description.

of the two variables using the MLRA (see Section 3.2.1), the correlation between the residual TWS and soil moisture (this include the trends and other signals) show a significant correlation value of 0.61 at $95 \%$ confidence level (Fig. 4c). However, the observed regression fit (Fig. 4a) makes it reasonable to employ soil moisture for a quantitative hydrological drought assessment over the Volta basin, especially with the limited availability of GRACE observations. The observed temporal variability between averaged TWS and soil moisture (Fig. 4b) leads us to the assumption that there were probably no significant subsurface storage changes in GRACEderived TWS over the basin during 2002-2007 as this period was largely characterised by 
hydrological droughts (see, MSDI of Fig. 2 at all monthly cumulations) and pronounced low lake level changes, in addition to the lack of significant positive trend in rainfall in the last decade (e.g., Ndehedehe et al., 2016). Hence, we speculate that strong deficits of soil moisture are somewhat analogous to TWS deficits over the Volta basin.

Results of the spatio-temporal drought analysis using GPCC-based precipitation for SPI 12 month indicate that the period during 1950-1968 was generally wet over the entire basin (Fig. 5) and is consistent with previous studies (Nicholson et al., 2000). Unlike the hydrological

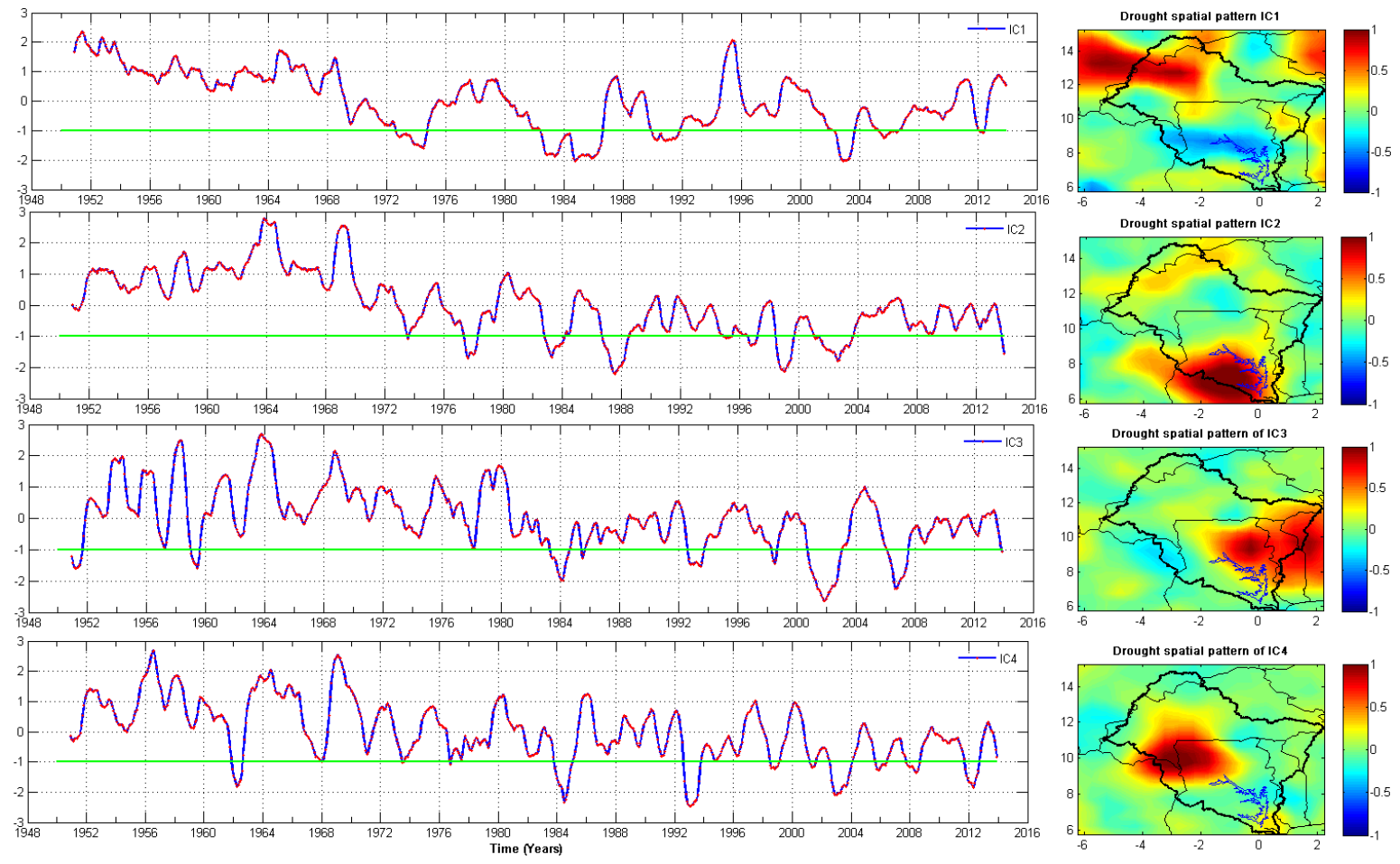

Figure 7: ICA-derived spatio-temporal hydrological drought patterns over the Volta basin using 12-month gridded SSI values. SSI values are computed using CPC-based soil moisture for the period 1950-2013. The variability of the ICA modes (i.e., the spatial and temporal drought patterns) for the decomposed SSI values within the basin are $11.6 \%, 9.7 \%, 8.7 \%$, and $6.9 \%$ for IC1, IC2, IC3, and IC4, respectively. Actual SSI values for drought classification and categorisation are jointly derived from the localised spatial drought pattern (right) and their corresponding temporal evolutions (left). The green solid line shows the drought threshold based on McKee et al. (1993) description.

drought analysis discussed in Section 4.1 above, here, the temporal variations of drought events and their corresponding spatial patterns are indicated. For instance, while the period between 2010 and 2013 show relatively moderate wet conditions (IC1, Fig. 5) in the north-western part of the basin (i.e., in Burkina Faso), the region in the lower Volta basin around the Lake Volta area in Ghana indicated an extreme dry condition during the same period though with a slight recovery in 2011 (IC2, Fig. 5). In fact, between late 2011 and 2013, the Lake area shows an 
extreme dry condition, consistent with a recent decline of about $2.25 \pm 0.10 \mathrm{~m} / \mathrm{yr}$ in Lake Volta water levels between 2011 and 2015 (not shown). The results of statistical decomposition of
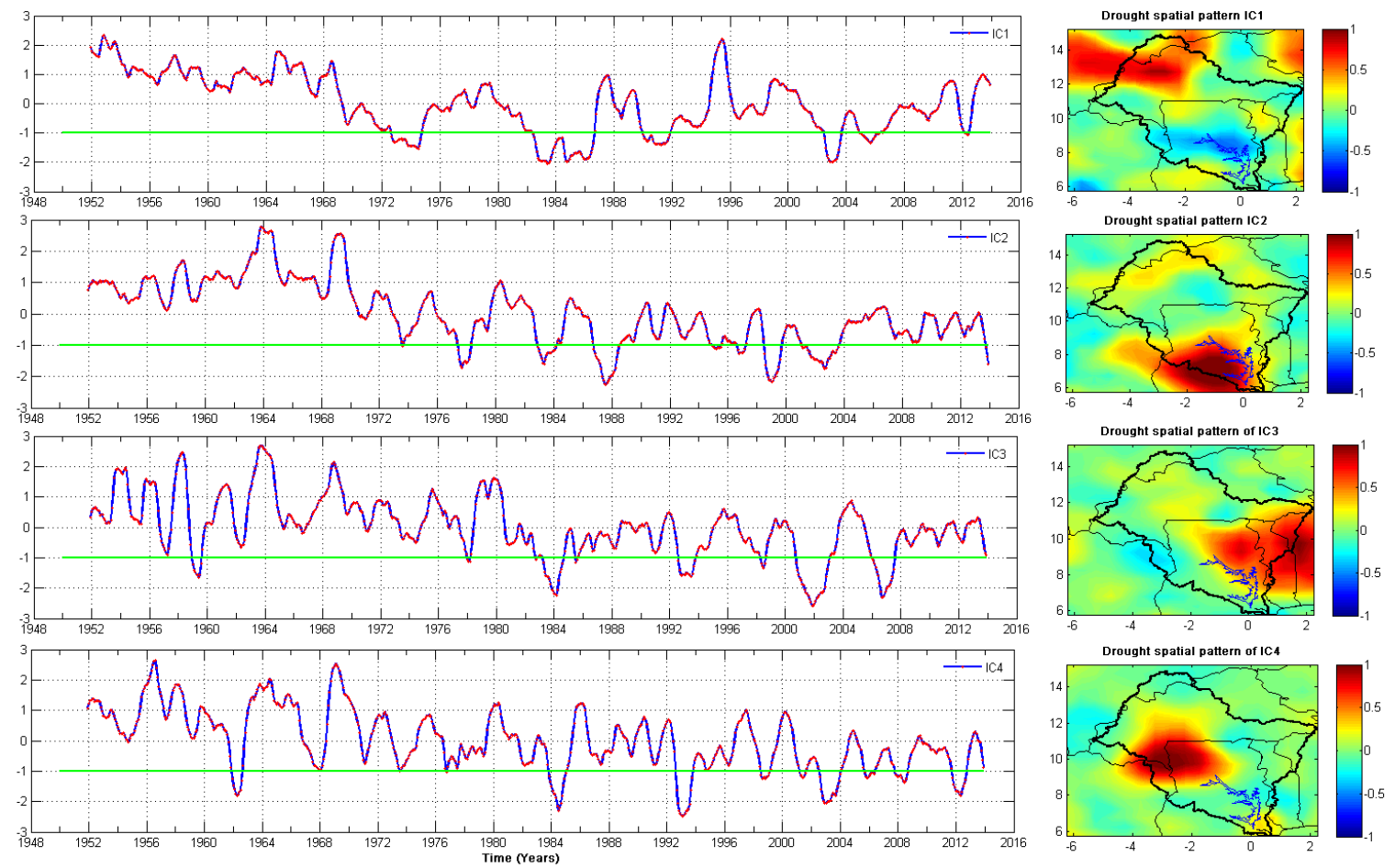

Figure 8: ICA-derived spatio-temporal hydrological drought patterns over the Volta basin using 24-month gridded SSI values. SSI values are computed using CPC-based soil moisture for the period 1950-2013. The variability of the ICA modes (i.e., the spatial and temporal drought patterns) for the decomposed SSI values within the basin are $8.6 \%, 8.2 \%, 7.3 \%$, and $5.6 \%$ for IC1, IC2, IC3, and IC4, respectively. Actual SSI values for drought classification and categorisation are jointly derived from the localised spatial drought pattern (right) and it corresponding temporal evolutions (left). The green solid line shows the drought threshold based on McKee et al. (1993) description.

SPI drought signals at 12 and 24 months cumulations are generally consistent except that drought frequency reduces at the SPI 24 month cumulation (Fig. 6) compared to the SPI drought signals at 12 months cumulations where drought frequencies are high (Fig. 5). More importantly, while the Lake Volta area still indicates an extreme drought condition even at the 24 month scale in the 2012/2013 period (IC4, Fig. 6), except for Ghana, observed drought episodes over the entire period (1950-2013) appear to be predominant in Burkina Faso (e.g., IC1 and IC3-IC4 Fig. 5). The spatial patterns of the observed drought signals are less patchy and more meaningful (i.e., Figs. 5 and 6 ) as they are well localised while their corresponding temporal evolutions are consistent with previous drought records of the basin (see, e.g., Masih et al., 2014; Bekoe and Logah, 2013; Owusu and Waylen, 2013; Kasei et al., 2010).

Similar to the SPI, SSI was constructed at 12 and 24 month scales and decomposed statis- 
tically using the ICA technique. The spatio-temporal patterns of hydrological drought for the SSI are rather consistent with those of SPI (i.e., Figs. 5 and 6) except for IC3 that indicates extreme drought conditions in 2000-2003 and 2006-2007 at the south-eastern part of the basin, i.e., in Ghana, Togo, and Benin republic (Figs. 7 and 8). For the lower Volta basin and the Lake area, which happen to be a center of high socio-economic activities, the strong fluctuating drought signals between 2008 and 2013 (Figs. 7 and 8) had serious hydrological implications for the basin, culminating in relatively strong decline of the Lake Volta water level. In fact, the southern part of the basin shows the apparent distinction between the wet periods of the 1950's and 1970's with those of recent times especially 2008-2013 (see IC2 and IC3 Figs. 7 and 8) probably due to a decline in the decadal mean precipitation. Further discussion on this (i.e., decadal precipitation patterns) is provided in Section 4.2.2.
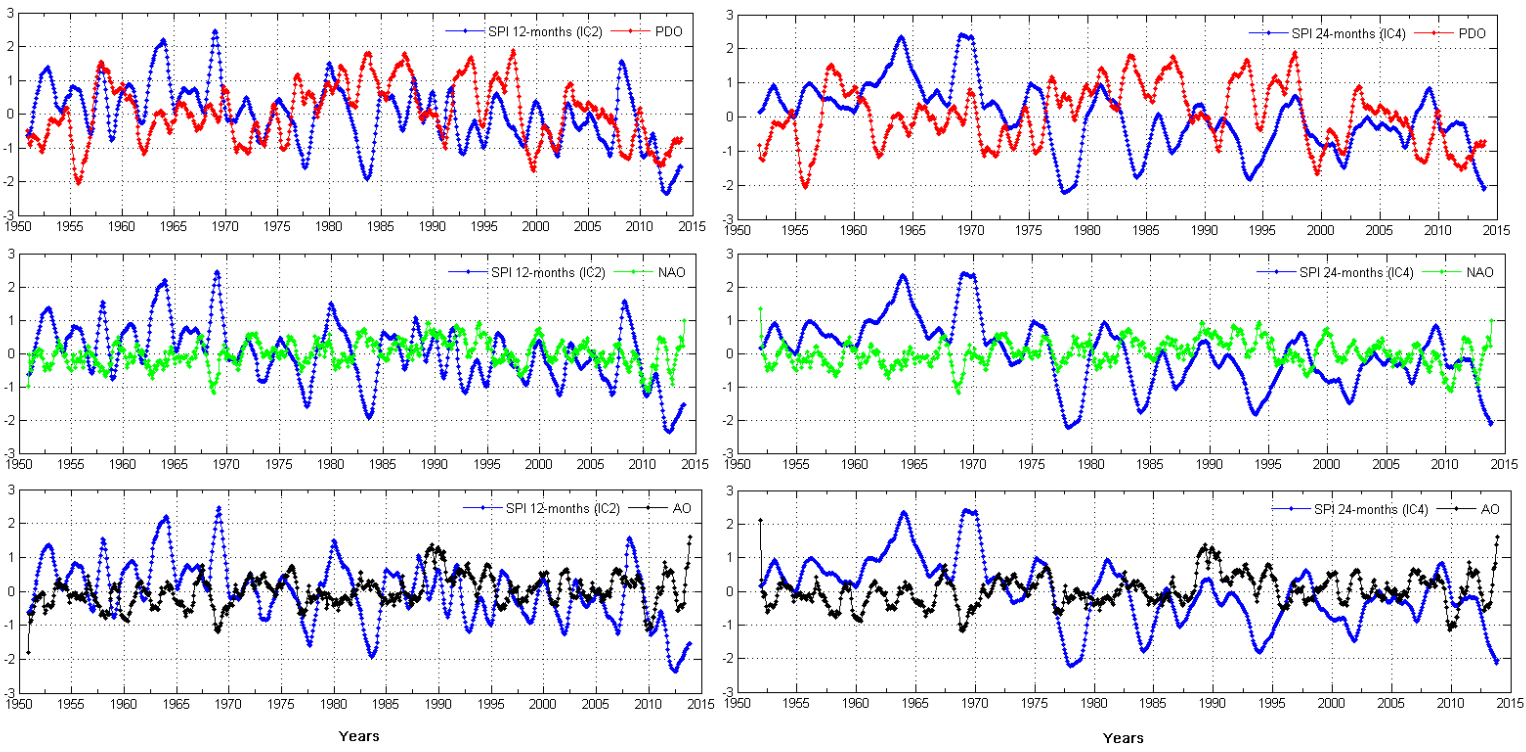

Figure 9: Influence of global climate teleconnection indices (i.e., 1950 to 2014) on temporal evolutions of hydrological droughts (i.e., 12 and 24 months SPI). The temporal drought pattern of ICA mode 2 and ICA mode 4 shown in Fig. 5 and Fig. 6, respectively are correlated with PDO (top), NAO (middle), and AO (bottom).

\subsubsection{SPI and Influence of Teleconnections}

Further, we attempt to explore the relationship between the ICA-derived SPI temporal evolutions with relevant global climate teleconnection indices that have been associated with rainfall variability in the region. This will help to examine the capability of ICA to highlight the impacts of teleconnections (see Section 3.1.6) on the observed drought signal (SPI). To this end, we correlated temporal evolutions of SPI for 12 and 24 months (i.e., IC1-IC4 of Figs. 5 and 6) with Pacific Decadal Oscillation (PDO), North Atlantic Oscillation (NAO), 
Table 1: Correlations between ICA-decomposed SPI-12 month temporal drought evolutions and global climate indices. The correlation coefficient with asterisk is insignificant at the $95 \%$ significant level using the Student T-test.

\begin{tabular}{ccccc}
\hline $\mathrm{S} / \mathrm{N}$ & $\mathrm{ICs}$ & $\mathrm{PDO}$ & $\mathrm{NAO}$ & $\mathrm{AO}$ \\
\hline 1 & $\mathrm{IC} 1$ & -0.39 & -0.28 & -0.18 \\
2 & $\mathrm{IC} 2$ & $-0.03^{*}$ & -0.21 & -0.27 \\
3 & $\mathrm{IC} 3$ & -0.18 & -0.18 & -0.18 \\
4 & $\mathrm{IC} 4$ & -0.25 & -0.24 & -0.25 \\
\hline
\end{tabular}

Table 2: Correlations between ICA-decomposed SPI-24 month temporal drought evolutions and remote climate indices. Correlation coefficients are all significant at the $95 \%$ significant level using the Student T-test.

\begin{tabular}{ccccc}
\hline $\mathrm{S} / \mathrm{N}$ & $\mathrm{ICs}$ & $\mathrm{PDO}$ & $\mathrm{NAO}$ & $\mathrm{AO}$ \\
\hline 1 & $\mathrm{IC} 1$ & -0.38 & -0.28 & -0.18 \\
2 & $\mathrm{IC} 2$ & -0.21 & -0.21 & -0.27 \\
3 & $\mathrm{IC} 3$ & -0.18 & -0.18 & -0.18 \\
4 & $\mathrm{IC} 4$ & -0.25 & -0.24 & -0.25 \\
\hline
\end{tabular}

and Arctic Oscillation (AO). In order to decrease the effects of strong inter-annual variability on the computed correlations (e.g., Awange et al., 2014), the temporal evolutions of SPI 12 and 24 months and the indices were smoothed using a 12-month moving average filter. The summary of the correlation results (see, Tables 1 and 2) performed at $95 \%$ confidence level over the entire period of the SPI data show that at 12 and 24 months SPI scale, PDO has a statistically significant negative correlation of -0.39 and -0.38 , respectively while NAO has a statistically significant negative correlations of -0.28 and -0.28 , respectively with IC1 of Figs. 5 and 6. For the Lake area where we analyse further the results of 12 and 24 months SPI correlations with the three indices (see, Fig. 9), the PDO, NAO and AO all have statistically significant negative correlations of $-0.25,-0.24$, and -0.25 (see, Table 2) with IC4 of Fig. 6, respectively. Generally the extreme wet periods as indicated by SPI 12 and 24 months (Fig. 9) coincide with the negative phase of the three indices while the observed dry periods (i.e., IC2 and IC4 of Figs. 5 and 6), coincide with the positive phase of all the indices as well. The coupled relationship of ENSO and Indian Ocean Dipole (IOD) were identified as major cause of the 1983/1984 drought that spread across the continent (e.g., Bader and Latif, 2011; Giannini et al., 2003) while over the Sahel, ENSO, NAO, Atlantic Multi Decadal Oscillation (AMO), and IOD were reported as having strong relationship with precipitation at different 
time scales (Okonkwo, 2014). Further, Brown et al. (2010) showed the results of the response of African land surface phenology to large scale climate oscillations, indicating that over West Africa, cumulative NDVI correlated with PDO in September-November period. However, in the current study, PDO, NAO, and AO are coupled ocean-atmosphere phenomena that are speculated as contributing to observed low frequency wet/dry periods in Burkina Faso (i.e., IC1 of Figs. 5 and 6) and the lower Volta region in Ghana (i.e., IC2 and IC4 of Figs. 5 and 6). Diatta and Fink (2014) reported a negative correlation of -0.38 and -0.30 (both significant at 95\% and 99\% confidence level) between PDO and rainfall indices of the Central Sahel (region including most parts of Burkina Faso) and West Sahel, respectively, somewhat consistent with our SPI drought temporal evolutions.

The physical causes of the PDO are not yet known and may be largely perceived as an irregular oscillation with unpredictable phase duration (Molion and Lucio, 2013). However, we highlight the PDO because it is a phenomenon that is not only characterised by low frequency variability but can also be employed for prospective future climate outlook. According to Molion and Lucio (2013) the PDO has been described as a long live ENSO episode with a cycle of 50 to 60 years, with each phase of the cycle lasting 25 to 30 years. In Fig. 9 (i.e., from the PDO time series), the period between 1950 and 1975 is characterised with the cold phase (CP) while 1977-1998 is characterised with a warm phase (WP). During the CP, it is observed that the PDO is associated with wet conditions while in contrast to the $\mathrm{CP}$, extreme dry periods are observed during the WP of the PDO. It is noteworthy that the CP of PDO running since 1999 till date has recorded at least two La-Niña periods leading to flood and extreme wet conditions in 2007 and 2010 in the basin. This period has seen the TWS and the Lake Volta water level rise in late 2007 up to $7 \mathrm{~m}$ in 2010 due to increased rainfall, leading to the spilling of the reservoir for the first time after so many years in November 2010 (see, e.g., Ndehedehe et al., 2016; Owusu and Waylen, 2013). The PDO has also been reported as a mechanism associated with rainfall variability in the Sahel. For instance, Molion and Lucio (2013) reported a decline in rainfall during the WP of PDO in the Sahel. Given that each phase of the PDO cycle lasts for about 25-30 years, it can be inferred that the current phase of the PDO may bring significant wetter conditions to the Sahel (i.e., in Burkina Faso) and the southern part of the basin at large in the near future. Molion and Lucio (2013) maintains this same position and have suggested a further clarification by establishing the sea surface temperature (SST) patterns of the Pacific Ocean as the duration of each phase of the PDO may not be predictable owing to its dependence on large magnitude seismic events, which 
could be scarce and random. On the whole, the influence of PDO, NAO, and AO, on the observed drought temporal evolutions as indicated in their correlations (see, Tables 1 and 2) further emphasizes the role of multiple dominant physical mechanisms in the climate extremes and variability of rainfall in the region (Druyan, 2011).
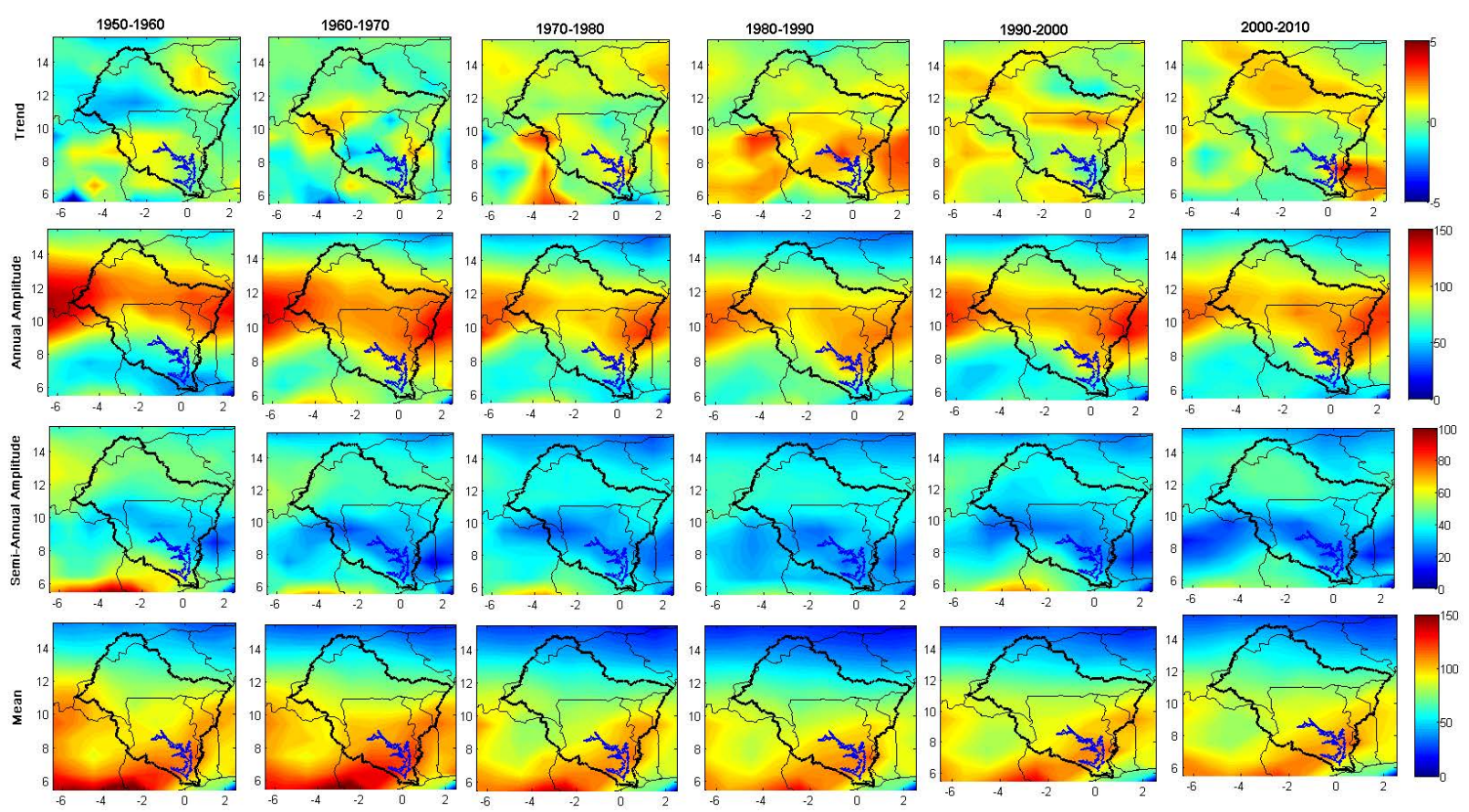

Figure 10: Decadal rainfall (mm) patterns over the Volta basin (1950-2010). Row 1: Trends in precipitation. Row 2: Mean annual amplitude of precipitation. Row 3: Mean semi-annual amplitude of precipitation. Row 4: Decadal mean precipitation

\subsubsection{Decadal Spatial Rainfall Patterns During 1950-2010}

The decadal rainfall patterns as analysed using the MLRA confirm that the periods between 1950-1960 and 1960-1970 were relatively wetter in the Volta basin as the mean annual amplitude and mean monthly rainfall respectively were relatively stronger than in other decades (Fig. 10). On a decadal-scale variability, our results are consistent with those of Nicholson et al. (2000) who showed that rainfall in the 1950's and 1960's were quite high as the mean regionally averaged rainfall were relatively high. The observed increase in precipitation trends spreading mostly in the southern basin during 1980-1990 period appears to be the strongest increase since 1950 (Row 1, Fig. 10). While the annual rainfall patterns in the 1980's were relatively weak due to the extreme drought of the 1983/1984 (see, e.g., Figs. 2-3 and 5-6), strong annual rainfall patterns similar to those of the 1950's is observed in northern Togo and Benin between 1990-2000 and 2000-2010 periods (Row 2, Fig. 10). This seems to be a recovery 

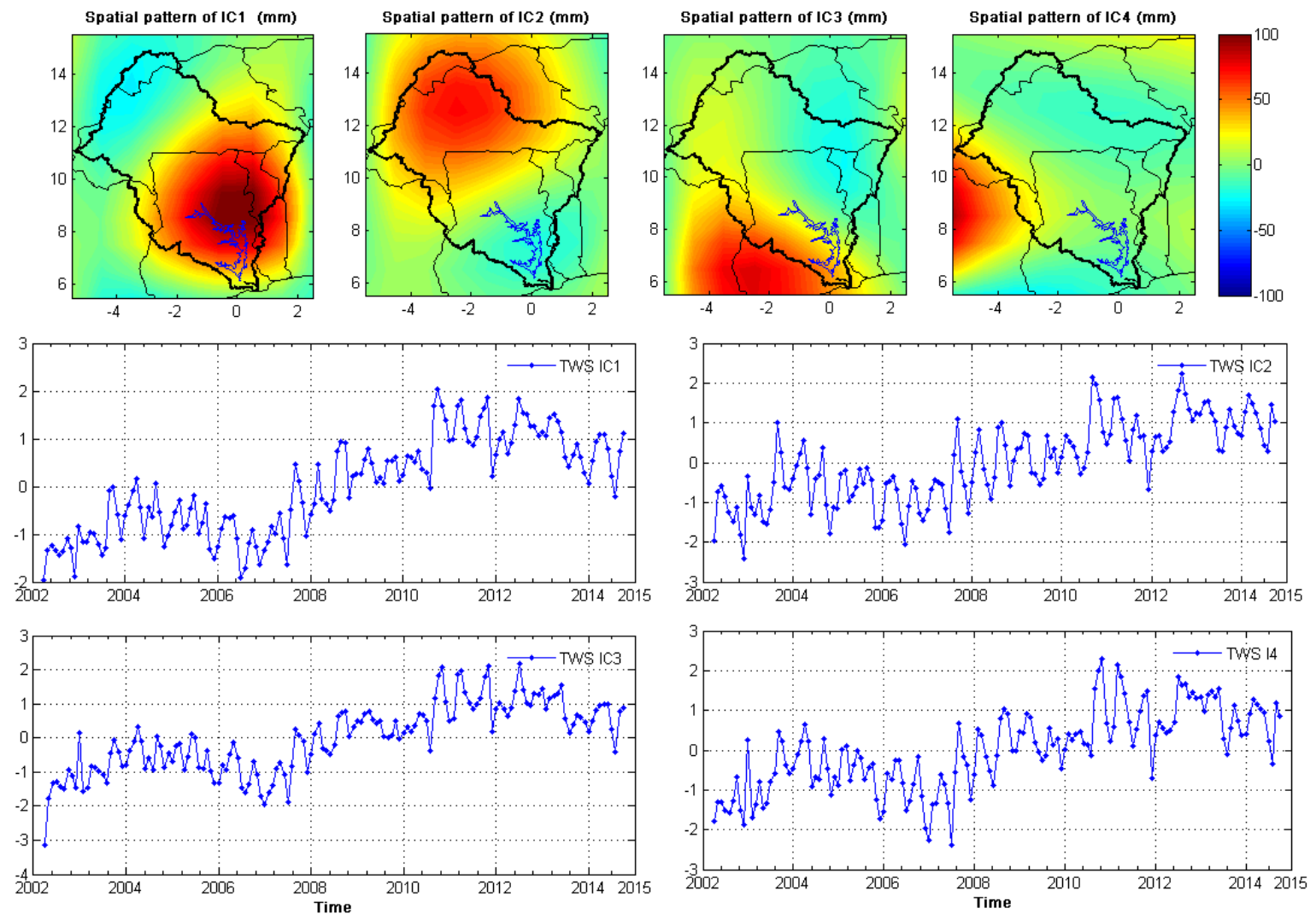

Figure 11: The independent components (bottom) of GRACE-derived TWS (i.e., after removing the annual signals over the Volta basin) corresponding to spatial patterns (top), which are scaled using the standard deviation of the computed independent components of the GRACE data. These independent components are unitless since they have been standardised using their standard deviations.

in the annual rainfall patterns of those countries (Row 2, Fig. 10). The semi annual rainfall patterns seem rather weak in the last decades compared to the 1950's (Row 3, Fig. 10) while the mean rainfall shows a general decline at the southern basin as rainfall reduces from about $150 \mathrm{~mm}$ in the 1950-1960 period to $110 \mathrm{~mm}$ during 2000-2010 period (Row 3 and 4, Fig. 10).

\subsection{Terrestrial Water Storage Changes}

We also analysed the GRACE-derived TWS using ICA and MLRA approaches in order to relate observed drought patterns to water availability and the basin's hydrological behaviour. The annual amplitude of GRACE-derived TWS was removed using MLRA through parameterisation of the harmonic components. The residuals, which contain semi-annual signal and trends were thereafter statistically decomposed into temporal and spatial patterns using the ICA method. The annual amplitude of TWS coincides with the annual amplitudes of rainfall (not shown). The first independent component (IC) of TWS shows the variability around the Lake area and the converging points of the three rivers (i.e., the Black Volta, White Volta 
and Oti Rivers, cf. Fig. 1) that forms the Volta river system in Ghana (IC1, Fig. 11). The
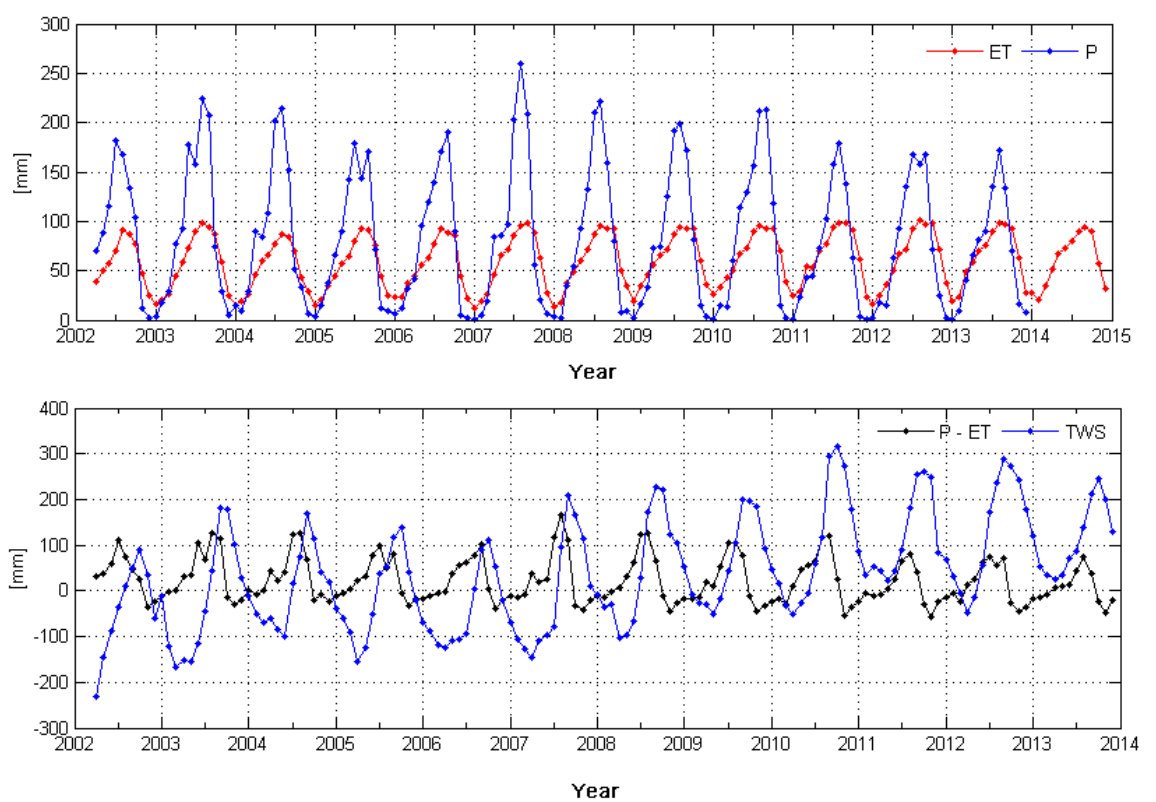

Figure 12: Time series of averaged precipitation, Evapotranspiration, and Net precipitation over the Volta basin. Top: GPCC-based precipitation and Modis derived Evapotranspiration over the entire basin. Bottom: Averaged GRACE-derived TWS changes and the corresponding precipitation minus evapotranspiration (net precipitation), a measure of water availability in basin.

other signals shown are those of Burkina Faso (IC2, Fig. 11), south east Ghana (IC3, Fig. 11), and northern Ivory Coast (IC4, Fig. 11). While the period between 2007 and 2010 indicate an increasing trend, the period between 2012 and 2014 show a decline in all sub-regions (i.e., IC1-IC4, Fig. 11). This observed pattern is stronger in IC1 of Fig. 11 due to the stronger loadings of its spatial patterns, possibly triggered by the presence of Lake Volta and the hydrology of the Volta river catchment in Ghana. Concerning the observed TWS signals in IC1 of Fig. 11, about $67 \%$ of the surface water resources in Ghana come from outside through the Volta river system, with Oti River contributing about $32 \%\left(11.2 \mathrm{~km}^{3}\right)$ while the Black Volta and White Volta contribute $24 \%\left(8.3 \mathrm{~km}^{3}\right)$ and $11 \%\left(3.9 \mathrm{~km}^{3}\right)$, respectively (Andreini et al., 2002). These surface water contributions from outside of Ghana, which are major triggers of observed hydrological signals in IC1 of Fig. 11, drain more than two-thirds of Ghana, with Lake Volta being formed by the Akosombo dam through the impoundment of these surface waters as they flow downstream. Analysis of recent satellite altimetry data (not shown) over Lake Volta showed an increase of $2.31 \pm 0.24 \mathrm{~m} / \mathrm{yr}$ corresponding to a water volume change of $19.635 \mathrm{~km}^{3}$ during the period of 2007/08-2010/12 over the Lake while the period 2011/01$2015 / 09$ showed a decline of $2.25 \pm 0.10 \mathrm{~m} / \mathrm{yr}$ coinciding with the period of observed decline in 
TWS change between 2012 and 2014 in Fig. 11. The 2007 La-Niña and the extreme wet condition of 2010 can be seen in the increasing trend in the observed TWS residual over the basin. The computed SPI, SRI, and MSDI in all aggregation scales over the basin (see, Fig. 2) also indicated similar increase between 2007 and 2010. This essentially demonstrates the utility of multiple standardised indicators to understand more vividly the sensitivity of lakes, reservoirs, and catchment systems to hydro-climatological and environmental changes. This apparently will largely support the management systems of water resources and the assessment of any anthropogenic influence (if any). The current study did not analyse human footprints on the basin's TWS. However, conflicting positions regarding the scientific evidence of anthropogenic influence on the inflows to the lake (see, e.g., Friesen et al., 2005; Andreini et al., 2002) is a critical subject for future considerations.

\subsection{Water Availability and Net Precipitation Over the Volta Basin}

The numerous water infrastructures, multiple sources of inflow into the Lake and the impact of water impoundments by the Akosombo dam in the Volta basin (e.g., Ahmed et al., 2014; Andreini et al., 2002) are just a few among the factors complicating the hydrology of the basin. The hydrology of the Volta basin is largely controlled by hydrological cycle components such as precipitation, runoff, and recharge and can be represented by the water balance equation

$$
\frac{d S(t)}{d t}=P(t)-E(t)-R(t)
$$

where $P, E, R$, and $d S$ are precipitation, evapotranspiration, runoff, change in storage (i.e., TWS), and $t$ the time, respectively. The yearly water availability i.e., the net precipitation can be given as

$$
P-E=\frac{d S(t)}{d t}+R(t)
$$

Net precipitation is important as it can help describe water deficit in a given hydrological system. The observed trends in $d S, P, E$ and the difference between $P$ and $E$ (i.e., $P-E$ ) were compared in order to understand the recent hydrological behaviour of the Volta basin. Rainfall indicated an insignificant decline of $1.25 \pm 1.74 \mathrm{~mm} / \mathrm{yr}$ during the 2002-2013 period while evapotranspiration showed a significant increase of $1.03 \pm 0.59 \mathrm{~mm} / \mathrm{yr}$ during the 20022014 period. TWS and $P-E$ over the basin indicated a significant increase of $16.24 \pm 2.28$ $\mathrm{mm} / \mathrm{yr}$ and a decrease of $2.53 \pm 1.22 \mathrm{~mm} / \mathrm{yr}$ at $95 \%$ confidence level respectively. Averaged 
rainfall over the entire basin shows a correlation of 0.84 at the same $95 \%$ confidence level with evapotranspiration, indicating consistent behaviour especially in its variability (Fig. 12, top). The impact of the 2007 ENSO event and other years (e.g., 2003-2004, 2008, and 2010) with relatively strong annual amplitudes are obvious (Fig. 12, top). However, between 2011 and 2013, annual peak rainfall, which usually occurs in August barely reached $170 \mathrm{~mm}$ compared to the more than $200 \mathrm{~mm}$ recorded in the years between 2007 and 2010 (Fig. 12, top). The observed less pronounced annual peak rainfall between 2011 and 2013 coincides with the observed less pronounced annual net precipitation over the basin (Fig. 12, top and bottom). The year 2010 was quite wet over the Volta basin, leading to strong amplitudes of TWS change (Fig. 12, bottom) consistent with observed trends and amplitudes of water storage and the Lake Volta water level in previous studies (e.g., Ndehedehe et al., 2016; Ahmed et al., 2014). However, the amplitudes of observed TWS during 2011-2013 period (Fig. 12, bottom) may not necessarily be due to increased rainfall as that period suggests a hydrological drought period in the Lake Volta area (see, IC1 and IC4 of Figs. 5 and 6, respectively). Over the entire basin, at 6, and 12 months aggregation scales and with respect to the mean of 1980, SPI and MSDI indicate a severe drought condition in 2011 that terminated in 2012 with a resurgence in 2013 (Figs. 2 and 3). While we attribute such changes in TWS during the period (20112013 in Fig. 12, bottom) to variations in lake level and river discharge, which has a non-linear relationship to rainfall as indicated earlier, apparently, from the statistical decomposition of TWS over the basin, the Lake Volta area, and the Oti river catchment area show a decline in observed residual TWS within the same period (IC1, Fig. 11). Consequently, the notion that the Volta basin may be predispose to drier conditions that could impact negatively on ecosystem services is affirmed, especially with lack of a significant positive trend in rainfall in the last decade.

\section{Conclusions}

In this study, we have examined the potentials of multiple drought indicators (SPI, SRI, SSI, and MSDI) and Gravity Recovery and Climate Experiment (GRACE) derived terrestrial water storage (TWS) to assess hydrological drought characteristics over the Volta basin. For the first time over the Volta basin, independent component analysis was employed to determine the space-time occurrence of hydrological drought in the basin. The influence of low frequency large scale oscillations on observed temporal evolutions of droughts over the basin was also investigated through correlation analysis. The results show that: 
(i) At all monthly cumulations, SPI time series computed over the basin show a relatively weak correlation with SRI with extreme wet periods exhibiting some lagged or non-linear relationships, reflecting a relatively slow response of discharge to extreme wet condition, especially after a previous extreme dry period. Also, the observed regression fit and relationship between soil moisture and TWS in Fig. 4a makes it reasonable to employ soil moisture at longer time scales (e.g., 12 months) for a quantitative hydrological drought assessment over the Volta basin, complementing the limited availability of GRACE observations.

(ii) The correlation between the two sets of MSDIs derived from combining precipitation/river discharge and precipitation/soil moisture indicates a significant value of 0.70 and show an improved skill in hydrological drought monitoring over the Volta basin. The SPI and SSI show a contrasting behaviour to SPI/SRI, indicating a correlation of 0.63 (i.e., at 12 month cumulation) and rather consistent in the observed dry and wet years.

(iii) The ICA-derived spatio-temporal hydrological drought patterns for the SPI and SSI are rather consistent and show Burkina Faso and the Lake Volta area as frequent drought zones. The spatial patterns of the observed drought signals are less patchy, and more meaningful as they are well localised while their corresponding temporal evolutions are generally consistent with previous drought records of the basin.

(iv) The statistically significant negative correlations of Pacific Decadal Oscillations (-0.39 and -0.25) with temporal evolutions of drought at Burkina Faso and Ghana suggest the possible influence of low frequency large scale oscillations in the observed wet and dry regimes over the basin. Besides the influence of Pacific Decadal Oscillation, the observed significant negative correlations of North Atlantic Oscillation, and Arctic Oscillation with the temporal evolutions of drought signals further regurgitates the role of multiple dominant physical mechanisms in the climate extremes and variability of rainfall in the region.

(v) The statistical decomposition of TWS (i.e., after removing the annual signal) indicate a decline in the Lake area and the Oti river catchment between 2012 and 2014, consistent with observed less pronounced annual peak rainfall and fluctuating drought conditions during the 2011-2013 period.

Finally, net precipitation show a significant decline while a more recent hydrological drought condition at the Lake Volta area is observed during the 2011-2013 period. The notion that the Volta basin may be predisposed to drier conditions that could impact negatively on ecosystem services is affirmed, especially with the lack of a significant positive trend in rainfall in the last decade. The current study did not analyse human footprints on the basin's TWS. 
However, conflicting positions regarding the scientific evidence of anthropogenic influence on the inflows to Lake Volta should be relevant and topical issues for future considerations. This study has confirmed that drought varies spatially and temporally in its frequency, duration, and severity. Hence, our space-time approach and the use of multiple climate variables in drought assessment over the Volta basin contributes to a broad framework for hydrological drought monitoring that will complement existing methodologies while looking forward to increase in the records of GRACE observations. The results and analyses from this study are based mostly on satellite measurements and model-based data. Hence, the results should be interpreted with caution as we look forward to new studies that will rely on large scale in-situ data over the region. 


\section{Acknowledgments}

Christopher E. Ndehedehe is grateful to Curtin University for his $\mathrm{PhD}$ funding through the Curtin Strategic International Research Scholarship (CSIRS) programme. The Authors are grateful to CSR, NOAA, and NASA for the data used in this study. The authors are also grateful to Water Research Institute of Ghana for the river discharge data of Akosombo station used in this study. Joseph Awange is grateful for the Brazilian Science Without Borders Program/CAPES Grant No. 88881.068057/2014-01 which supported his stay in UFPE Federal University of Pernambuco, Brazil. We also thank the editor and the three anonymous reviewers for their very useful comments, which helped improved the manuscript. 


\section{References}

Ahmed, M., Sultan, M., J.Wahr, and Yan, E. (2014). The use of GRACE data to monitor natural and anthropogenic induced variations in water availability across Africa. Earth Science Reviews, 136:289-300. doi:10.1016/j.earscirev.2014.05.009.

Ali, A. and Lebel, T. (2009). The Sahelian standardized rainfall index revisited. International Journal Of Climatology, 29:1705-1714. doi:10.1002/joc.1832.

Andreini, M., Vlek, P., and Giesen, N. V. D. (2002). Water sharing in the Volta basin. FRIEND, pages 329-335. Proceedings of the Fourth International FRIEND Conference, South Africa.

Awange, J., Forootan, E., Ferreira, V., Khandu, Andam-Akorful, S., Agutu, N., and He, X. (2016). Uncertainties in remotely sensed precipitation data over Africa. International Journal Of Climatology, 36:303-323. doi:10.1002/joc.4346.

Awange, J., Forootan, E., Kuhn, M., Kusche, J., and Heck, B. (2014). Water storage changes and climate variability within the Nile Basin between 2002 and 2011. Advances in Water Resources, 73(0):1 - 15. doi:10.1016/j.advwatres.2014.06.010.

Bader, J. and Latif, M. (2011). The 1983 drought in the West Sahel: A case study. Climate Dynamics, 36(3-4):463-472. doi:10.1007/s00382-009-0700-y.

Baur, O., Kuhn, M., and Featherstone, W. E. (2009). GRACE-derived ice-mass variations over Greenland by accounting for leakage effects. Journal of Geophysical Research: Solid Earth, 114(B6):B06407. doi:10.1029/2008JB006239.

Bazrafshan, J., Hejabi, S., and Rahimi, J. (2014). Drought monitoring using the multivariate standardized precipitation index (MSPI). Water Resources Mangagement, 28:1045-1060. doi:10.1007/s11269-014-0533-2.

Becker, A., Finger, P., Meyer-Christoffer, A., Rudolf, B., Schamm, K., Schneider, U., and Ziese, M. (2013). A description of the global land-surface precipitation data products of the Global Precipitation Climatology Centre with sample applications including centennial (trend) analysis from 1901 to present. Earth System Science Data, 5(1):71-99. doi:10.5194/essd-5-71-2013. 
Bekoe, E. O. and Logah, F. Y. (2013). The impact of droughts and climate change on electricity generation in Ghana. Environmental Sciences, 1(1):13-24.

Bloomfield, J. P. and Marchant, B. P. (2013). Analysis of groundwater drought building on the standardised precipitation index approach. Hydrology and Earth System Sciences, 17(12):4769-4787. doi:10.5194/hess-17-4769-2013.

Boergens, E., Rangelova, E., Sideris, M. G., and Kusche, J. (2014). Assessment of the capabilities of the temporal and spatiotemporal ICA method for geophysical signal separation in GRACE data. Journal of Geophysical Research Solid Earth, 119:4429-4447,. doi:10.1002/2013JB010452.

Bonaccorso, B., Bordi, I., Cancelliere, A., Rossi, G., and Sutera, A. (2003). Spatial variability of drought: An analysis of the SPI in Sicily. Water Resources Management, 17(4):273-296. doi:10.1023/A:1024716530289.

Bonsor, H. C. and MacDonald, A. M. (2011). An initial estimate of depth to groundwater across Africa. British Geological Surveys Groundwater Science OR/11/067. Retrieved from: http://nora.nerc.ac.uk/id/eprint/17907, Accessed 15th June, 2015.

Brown, M. E., de Beurs, K., and Vrieling, A. (2010). The response of African land surface phenology to large scale climate oscillations. Remote Sensing of Environment, 114(10):2286 - 2296. doi:10.1016/j.rse.2010.05.005.

Cardoso, J.-F. (1991). Super-symmetric decomposition of the fourth-order cumulant tensor, blind identification of more sources than sensors. Retrieved from:http://perso.telecomparistech.fr/ cardoso/Papers.PDF/icassp91.pdf. Accessed 15 January 2016.

Cardoso, J. F. (1999). High-Order contrasts for Independent Component Analysis. Neural Computation, 11:157-192.

Cardoso, J. F. and Souloumiac, A. (1993). Blind beamforming for non-gaussian signals. IEE Proceedings, 140(6):362-370.

Cheng, M. K., Tapley, B. D., and Ries, J. C. (2013). Deceleration in the Earth's oblateness. Journal of Geophysical Research, 118:1-8. doi:10.1002/jgrb.50058.

Common, P. (1994). Independent component analysis, A new concept? Signal Processing, $36: 287-314$. 
Crowley, J. W., Mitrovica, J. X., Bailey, R. C., Tamisiea, M. E., and Davis, J. L. (2006). Land water storage within the Congo Basin inferred from GRACE satellite gravity data. Geophysical Research Letters, 33(19):L19402. doi:10.1029/2006GL027070.

Diatta, S. and Fink, A. H. (2014). Statistical relationship between remote climate indices and West African monsoon variability. International Journal of Climatology, 34(12):3348-3367. doi:0.1002/joc.3912.

Druyan, L. M. (2011). Studies of 21st-century precipitation trends over West Africa. International Journal of Climatology, 31(10):1415-1424. doi:10.1002/joc.2180.

Fan, Y. and Dool, H. V. (2004). Climate prediction center global monthly soil moisture data set at $0.5^{\circ}$ resolution for 1948 to present. Journal Of Geophysical Research, 109:D10102. doi:10.1029/2003JD004345.

Farahmand, A. and AghaKouchak, A. (2015). A generalized framework for deriving nonparametric standardized drought indicators. Advances in Water Resources, (76):140-145. doi:/10.1016/j.advwatres.2014.11.012.

Fenoglio-Marc, L., Rietbroek, R., Grayek, S., Becker, M., Kusche, J., and Stanev, E. (2012). Water mass variation in the Mediterranean and Black Seas. Journal of Geodynamics, 5960:168 182 .

Ferreira, V., Andam-Akorful, S. A., He, X., and Xiao, R. (2014). Estimating water storage changes and sink terms in Volta Basin from satellite missions. Water Science and Engineering, 7(1):5-16. doi:10.3882/j.issn.1674-2370.2014.01.0028.

Ferreira, V. and Asiah, Z. (2015). An investigation on the closure of the water budget methods over Volta Basin using multi-satellite data. International Association of Geodesy Symposia. doi:10.1007/1345-2015-137.

Forootan, E., Awange, J., Kusche, J., Heck, B., and Eicker, A. (2012). Independent patterns of water mass anomalies over Australia from satellite data and models. Remote Sensing of Environment, 124:427-443.

Forootan, E. and Kusche, J. (2012). Separation of global time-variable gravity signals into maximally independent components. Journal of Geodesy, 86(7):477-497. doi:10.1007/s00190011-0532-5. 
Frappart, F., Ramillien, G., Leblanc, M., Tweed, S. O., Bonnet, M.-P., and Maisongrande, P. (2011). An independent component analysis filtering approach for estimating continental hydrology in the GRACE gravity data. Remote Sensing of Environment, 115(1):187 - 204. doi:doi.org/10.1016/j.rse.2010.08.017.

Friesen, J., Andreini, M., Andah, W., Amisigo, M. A., and Giesen, N. V. D. (2005). Storage capacity and long-term water balance of the Volta Basin, West Africa. Proceedings of symposium S6 held during the Seventh IAHS Scientific Assembly, Brazil. Retrieved from:http://iahs.info/uploads/dms/13203.2220138-14520Foz20S6-21420Friesen.pdf, Accessed 18 December, 2015.

Fukuda, Y., Yamamoto, K., Hasegawa, T., Nakaegawa, T., Nishijima, J., and Taniguchi, M. (2009). Monitoring groundwater variation by satellite and implications for insitu gravity measurements. Science of The Total Environment, 407(9):3173 - 3180. doi:10.1016/j.scitotenv.2008.05.018.

Giannini, A., Saravanan, R., and Chang, P. (2003). Oceanic forcingof Sahel rainfall on interannual to decadal time scales. Science, 302(5647):1027-1030. doi:10.1126/science.1089357.

Giesen, N. V. D., Andreini, M., Edig, A. V., and Vlek, P. (2002). Competition for water resources of the Volta basin. Regional Management of Water Resources, (268):199205. Retrievedfrom: http://www.zef.de/fileadmin/template/Glowa/Downloads/, Accessed 12 November, 2014.

Giesen, N. V. D., Liebe, J., and Jung, G. (2010). Adapting to climate change in the Volta Basin, West Africa . Current Science, 98(8):1033-1037.

Greve, P., Orlowsky, B., Mueller, B., Sheffield, J., Reichstein, M., and Seneviratne, S. L. (2014). Global assessment of trends in wetting and drying over land. Nature Geoscience, 7:716-721. doi:10.1038/NGE02247.

Gringorten, I. I. (1963). A plotting rule for extreme probability paper. Journal of Geophysical Research, 68(3):813-814.

Hao, Z. and AghaKouchak, A. (2013). Multivariate standardized drought index: A parametric multi-index model. Advances in Water Resources, (57):12-18. doi:10.1016/j.advwatres.2013.03.009. 
Hao, Z. and AghaKouchak, A. (2014). A nonparametric multivariate multi-index drought monitoring framework. Journal of Hydrometeorology, 15(1):89-101. doi:10.1175/JHM-D12-0160.1.

Hayes, M. J. (2007). Drought indices. Intermountain West Climate Summary. Retrieved from: www.colorado.edu/climate/iwcs/archive/IWCS-2007-July-feature.pdf Accessed 9 December, 2015.

Hayes, M. J., Svoboda, M. D., Wilhite, D. A., and Vanyarkho, O. V. (1999). Monitoring the 1996 drought using the standardized precipitation index. Bulletin of the American Meteorological Society, 80:429-438. doi:10.1175/1520-0477(1999)080;0429:MTDUTS ¿2.0.CO;2.

Hoekstra, A. Y. and Mekonnen, M. M. (2012). The water footprint of humanity. PNAS, 109(9):32323237. doi:10.1073/pnas.1109936109.

Joetzjer, E., Douville, H., Delire, C., Ciais, P., Decharme, B., and Tyteca, S. (2013). Hydrologic benchmarking of meteorological drought indices at interannual to climate change timescales: a case study over the amazon and mississippi river basins. Hydrology and Earth System Sciences, 17(12):4885-4895. doi:10.5194/hess-17-4885-2013.

Jolliffe, I. T. (2002). Principal component analysis (second edition). Springer Series in Statistics. Springer, New York.

Kasei, R., Diekkrüger, B., and Leemhuis, C. (2010). Drought frequency in the Volta Basin of West Africa. Sustainability Science, 5(1):89-97.

Keys, P., Barnes, E. A., van der Ent, R. J., and Gordon, L. J. (2014). Variability of moisture recycling using a precipitationshed framework. Hydrology and Earth System Science, 18:3937-3950. doi:10.5194/hess-18-3937-2014.

Keys, P., van der Ent, R. J., Gordon, L. J., Hoff, H., Nikoli, R., and Savenije, H. H. G. (2012). Analyzing precipitationsheds to understand the vulnerability of rainfall dependent regions. Biogeosciences, 9:733-746. doi:10.5194/bg-9-733-2012.

Komuscu, A. U. (1999). Using the SPI to analyze spatial and temporal patterns of drought in Turkey. Drought Network News, 11(1):7-13.

Kumar, R., Musuuza, J. L., Loon, A. F. V., Teuling, A. J., Barthel, R., Broek, J. T., Mai, J., Samaniego, L., and Attinger, S. (2015). Multiscale evaluation of the standardized pre- 
cipitation index as a groundwater drought indicator. Hydrology and Earth System Sciences, 12:74057436. doi:10.5194/hessd-12-7405-2015.

Kusche, J., Schmidt, R., Petrovic, S., and Rietbroek, R. (2009). Decorrelated GRACE timevariable gravity solutions by GFZ, and their validation using a hydrological model. Journal of Geodesy, 83(10):903-913. doi:10.1007/s00190-009-0308-3.

Lacombe, G., McCartney, M., and Forkuor, G. (2012). Drying climate in Ghana over the period 19602005: evidence from the resampling-based Mann-Kendall test at local and regional levels. Hydrological Sciences Journal, 57(8):1594-1609. doi:10.1080/02626667.2012.728291.

Landerer, F. W. and Swenson, S. C. (2012). Accuracy of scaled GRACE terrestrial water storage estimates. Water Resources Research, 48(4):W04531. doi:10.1029/2011WR011453.

Li, B. and Rodell, M. (2015). Evaluation of a model-based groundwater drought indicator in the conterminous U.S. . Journal of Hydrology, 526:78 - 88. doi:10.1016/j.jhydrol.2014.09.027.

Lloyd-Hughes, B. (2012). A spatio-temporal structure-based approach to drought characterisation. International Journal of Climatology, 32(3):406-418. doi:10.1002/joc.2280.

Long, D., Longuevergne, L., and Scanlon, B. R. (2015). Global analysis of approaches for deriving total water storage changes from GRACE satellites. Water Resources Research, 51(4):2574-2594. doi:10.1002/2014WR016853.

Loon, A. F. V. (2015). Hydrological drought explained. WIREs Water, 2:359-392. doi:10.1002/wat2.1085.

MacDonald, A. M., Bonsor, H. C., Dochartaigh, B. E. O., and Taylor, R. G. (2012). Quantitative maps of groundwater resources in Africa. Environmental Research Letters, 7. doi:10.1088/1748-9326/7/2/024009.

Masih, I., Maskey, S., Mussá, F. E. F., and Trambauer, P. (2014). A review of droughts on the African continent: a geospatial and long-term perspective. Hydrology and Earth System Sciences, 18(9):3635-3649. doi:10.5194/hess-18-3635-2014.

McKee, T. B., Doeskin, N. J., and Kieist, J. (1993). The relationship of drought frequency and duration to time scales. Conference on Applied Climatology, American Meteorological Society,Boston, Massachusetts, pages 179-184. Retrieved 
from:www.ccc.atmos.colostate.edu/relationshipofdroughtfrequency.pdf. Accessed 27 June, 2014.

McKee, T. B., Doeskin, N. J., and Kieist, J. (1995). Drought monitoring with multiple time scales. Conference on Applied Climatology, American Meteorological Society, Boston, Massachusetts, pages 233-236. Retrieved from:www.southwestclimatechange.org/node/911. Accessed 13 July, 2014.

Mishra, A. K. and Singh, V. P. (2010). A review of drought concepts. Journal of Hydrology, 391:202-216. doi:10.1016/j.jhydrol.2010.07.012.

Molion, L. C. B. and Lucio, P. S. (2013). A note on Pacific Decadal Oscillation, El Nino Southern Oscillation, Atlantic Multidecadal Oscillation and the Intertropical Front in Sahel, Africa. Atmospheric and Climate Sciences, 3:269-274. doi:10.4236/acs.2013.33028.

Mu, Q., Zhao, M., and Running, S. W. (2011). Improvements to a MODIS global terrestrial evapotranspiration algorithm. Remote Sensing of Environment, 115(8):1781 - 1800. doi:10.1016/j.rse.2011.02.019.

Nalbantis, I. and Tsakiris, G. (2009). Assessment of hydrological drought revisited. Water Resources Management, 23:881-897. doi:10.1007/s11269-008-9305-1.

Ndehedehe, C., Awange, J., Agutu, N., Kuhn, M., and Heck, B. (2016). Understanding changes in terrestrial water storage over West Africa between 2002 and 2014. Advances in Water Resources, 88:211-230. doi:10.1016/j.advwatres.2015.12.009.

Nichol, J. E. and Abbas, S. (2015). Integration of remote sensing datasets for local scale assessment and prediction of drought. Science of The Total Environment, 505:503 - 507. doi:10.1016/j.scitotenv.2014.09.099.

Nicholson, S. E., Some, B., and Kone, B. (2000). An Analysis of Recent Rainfall Conditions in West Africa, Including the Rainy Seasons of the $1997 \mathrm{El}$ Nin̈o and the 1998 La Nia Years. Journal of Climate, 13(14):2628-2640. doi:10.1175/15200442(2000)013¡2628:AAORRC ¿2.0.CO;2.

Nicholson, S. E., Some, B., Mccollum, J., Nelkin, E., Klotter, D., Berte, Y., Diallo, B. M., Gaye, I., Kpabeba, G., Ndiaye, O., Noukpozounkou, J. N., Tanu, M. M., Thiam, A., Toure, A. A., and Traore, A. K. (2003). Validation of TRMM and other rainfall estimates with a 
high-density gauge datasets for West Africa. Part I: Validation of GPCC rainfall product and pre-TRMM satellite and blended products. Journal of Applied Meteorology, 42:1337-1354. doi:10.1175/1520-0450(2003)042C1337:VOTAOR3E2.0.CO;2.

Odekunle, T. O. and Eludoyin, A. O. (2008). Sea surface temperature patterns in the Gulf of Guinea: their implications for the spatio-temporal variability of precipitation in West Africa. International Journal Of Climatology, 28:15071517. doi:10.1002/joc.1656.

Oguntunde, P. G., Friesen, J., van de Giesen, N., and Savenije, H. H. (2006). Hydroclimatology of the Volta River Basin in West Africa: Trends and variability from 1901 to 2002. Physics and Chemistry of the Earth, Parts A/B/C, 31(18):1180 - 1188. doi:10.1016/j.pce.2006.02.062.

Okonkwo, C. (2014). An Advanced Review of the Relationships between Sahel Precipitation and Climate Indices: A Wavelet Approach. International Journal of Atmospheric Sciences, 2014:11. doi:10.1155/2014/759067.

Owusu, K. and Waylen, P. (2009). Trends in spatio-temporal variability in annual rainfall in Ghana (1951-2000). Weather, 64(5):115-119.

Owusu, K. and Waylen, P. (2013). The changing rainy season climatology of mid-Ghana. Theoretical and Applied Climatology, 112(3):419-430. doi:10.1007/s00704-012-0736-5.

Owusu, K., Waylen, P., and Qiu, Y. (2008). Changing rainfall inputs in the Volta basin: implications for water sharing in Ghana. GeoJournal, 71(4):201-210. doi:10.1007/s10708008-9156-6.

Paeth, H., Fink, A., Pohle, S., Keis, F., Machel, H., and Samimi, C. (2012). Meteorological characteristics and potential causes of the 2007 flood in sub-Saharan Africa. International Journal of Climatology, 31:1908-1926. doi:10.1002/Joc.2199.

Preisendorfer, R. (1988). Principal component analysis in meteorology and oceanography. Developments in Atmospheric Science 17. Elsevier, Amsterdam.

Ramillien, G., Bouhours, S., Lombard, A., Cazenave, A., Flechtner, F. R., and Schmidt (2008). Land water storage contribution to sea level from GRACE geoid data over 2003-2006. Global and Planetary Change, 60(3-4):381-392. doi:10.1016/j.gloplacha.2007.04.002. 
Rodrguez-Fonseca, B., Janicot, S., Mohino, E., Losada, T., Bader, J., Caminade, C., Chauvin, F., Fontaine, B., Garca-Serrano, J., Gervois, S., Joly, M., Polo, I., Ruti, P., Roucou, P., and Voldoire, A. (2011). Interannual and decadal SST-forced responses of the West African monsoon. Atmospheric Science Letters, 12:67-74. doi:10.1002/asl.308.

Rouault, M. and Richard, Y. (2003). Intensity and spatial extension of drought in South Africa at different time scales. Water $S A, 29(4): 489-500$.

Santos, J. a. F., Pulido-Calvo, I., and Portela, M. M. (2010). Spatial and temporal variability of droughts in Portugal. Water Resources Research, 46(3):W03503. doi:10.1029/2009WR008071.

Schneider, U., Becker, A., Finger, P., Meyer-Christoffer, A., Ziese, M., and Rudolf, B. (2014). GPCC's new land surface precipitation climatology based on quality-controlled in situ data and its role in quantifying the global water cycle. Theoretical and Applied Climatology, 115(1-2):15-40. doi:10.1007/s00704-013-0860-x.

Shukla, S. and Wood, A. W. (2008). Use of a standardized runoff index for characterizing hydrologic drought. Geophysical Research Letters, 35(2):L02405. 10.1029/2007GL032487.

Sneeuw, N., Lorenz, C., Devaraju, B., Tourian, M., Riegger, J., Kunstmann, H., and Bárdossy, A. (2014). Estimating runoff using hydro-geodetic approaches. Surveys in Geophysics, 35(6):1333-1359. doi:10.1007/s10712-014-9300-4.

Swenson, S., Chambers, D., and Wahr, J. (2008). Estimating geocenter variations from a combination of GRACE and ocean model output. Geophysical Research Letters, 31:1-4. doi:10.1029/ 2004GL019920.

Swenson, S. and Wahr, J. (2007). Multi-sensor analysis of water storage variations of the Caspian Sea. Geophysical Research Letters, 34(16). doi:10.1029/2007gl030733.

Tapley, B., Bettadpur, S., Watkins, M., and Reigber, C. (2004). The Gravity Recovery and Climate Experiment: Mission overview and early results. Geophysical Research Letters, 31:1-4. doi:10.1029/ 2004GL019920.

Theis, F. J., Gruber, P., Keck, I. R., Meyer-bse, A., and Lang, E. W. (2005). Spatiotemporal blind source separation using double-sided approximate joint diagonalization. In In Proc. EUSIPCO 2005. 
Tourian, M., Elmi, O., Chen, Q., Devaraju, B., Roohi, S., and Sneeuw, N. (2015). A spaceborne multisensor approach to monitor the desiccation of Lake Urmia in Iran . Remote Sensing of Environment, 156:349 - 360. doi:10.1016/j.rse.2014.10.006.

Vicente-Serrano, S. M. (2006). Spatial and temporal analysis of droughts in the Iberian Peninsula (19102000). Hydrological Sciences Journal, 51(1):83-97. doi:10.1623/hysj.51.1.83.

Wahr, J., Molenaar, M., and Bryan, F. (1998). Time variability of the Earth's gravity field: Hydrological and oceanic effects and their possible detection using GRACE. Journal of Geophysical Research-Solid Earth, 103(B12):30205-30229. doi:10.1029/98jb02844.

Wouters, B. and Schrama, E. J. O. (2007). Improved accuracy of GRACE gravity solutions through empirical orthogonal function filtering of spherical harmonics. Geophysical Research Letters, 34(23):L23711. doi:10.1029/2007GL032098.

Ziehe, A. (2005). Blind source separation based on joint diagonalization of matrices with applications in biomedical signal processing. PhD thesis, Universitat Potsdam. Retrieved from:http://en.youscribe.com/catalogue/reports-and-theses/knowledge/blindsource-separation-based-on-joint-diagonalization-of-matrices-1424347. Accessed 15 May 2015 . 